\title{
Folclore, tipismo y política. Los trajes regionales de la Sección Femenina de Falange
}

Folklore, typecasting and politics. The costumes of the Women's Section of the Falange

\author{
Carmen Ortiz \\ Centro de Ciencias Humanas y Sociales. CSIC. Madrid \\ carmen.ortiz@cchs.csic.es
}

\author{
30 ANIVERSARIO DE LA GAZETA DE ANTROPOLOGÍA \\ NÚMERO COORDINADO POR FRANCISCO CHECA OLMOS Y CELESTE JIMÉNEZ DE MADARIAGA
}

\begin{abstract}
RESUMEN
Los trajes regionales fueron un elemento preeminente en la utilización que la dictadura hizo del folclore, y específicamente de la música y el espectáculo de la danza, con fines ideológicos y de propaganda política, tanto en el interior como en el exterior. Esta tarea, como otras de tipo educativo y de control, fue expresamente encargada y desempeñada por la Sección Femenina de la única organización política del régimen, la Falange Española, Tradicionalista y de las JONS. Partiendo de la idea de que los llamados trajes regionales españoles han funcionado y siguen funcionando en la actualidad como una construcción cultural compleja, se expondrá la importancia en este proceso de 'invención de la tradición' del momento político representado por el franquismo y cuáles fueron sus bases ideológicas.
\end{abstract}

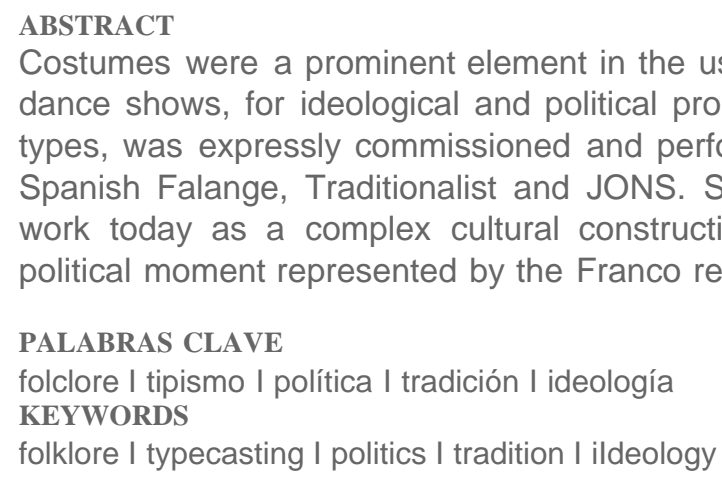

PALABRAS CLAVE

folclore I tipismo I política I tradición I ideología

KEYWORDS

folklore I typecasting I politics I tradition I ildeology

Costumes were a prominent element in the use made of folklore by the Franco dictatorship in Spain, and specifically music and dance shows, for ideological and political propaganda, both indoors and outdoors. This task, like other educational and control types, was expressly commissioned and performed by the Women's Section of the only political organization of the regime, the Spanish Falange, Traditionalist and JONS. Starting from the idea that the so-called Spanish costumes have worked and still work today as a complex cultural construction, will outline the importance in this process of "invention of tradition" of the political moment represented by the Franco regime and define their ideological bases.

\section{Folclore y política durante el franquismo}

Cuando el régimen franquista consigue imponerse en el país después de la guerra, una de las tareas urgentes que debe acometer es la "reconstrucción" de la Patria (como gustaron de llamar a España los sublevados contra el gobierno de la República). Esta reconstrucción no era solo material; también había que restaurar una política nacional que dejara claras las nuevas condiciones de vida social y política a las que su victoria en la guerra había dado paso. Es decir, la reconstrucción se basaba la creación de un repertorio cultural y patrimonial acorde con el sistema político totalitario impuesto tras la guerra. La tarea que el régimen franquista acomete es la creación de una "Nueva España", que se define mediante la permanente oposición frente a los caracteres y rasgos de la España republicana, pero a la vez se configura como una representación absoluta de la "España eterna" de la que se consideraba heredera. Una nueva nación cuyo futuro se construye paradójicamente en base a los principios de una Vieja España, eso sí reescrita y reinventada a través de una ideología reaccionaria. Las señas de identidad de esa Nueva España en construcción se buscarán en los estratos más genuinos y profundos de la nación: la base común y originaria de este edificio será la "hispanidad"; un ambiguo y difuso sustrato étnico- 
lingüístico-político, que se quería hacer funcionar de un modo parecido a la "germanidad" del nazismo.

En esta tarea, la construcción del nuevo repertorio patrimonial que va a guiar la política de representación nacional del régimen va a estar determinada por un doble principio: la memorialización y la moralización del conflicto (Viejo-Rose 2011: 46). Se perseguirá siempre el recuerdo permanente de la división entre los vencedores y los vencidos; es decir, la construcción de una memoria partida (Castro 2008). El paisaje cultural que se impone entonces a los españoles deberá legitimar y dar coherencia a esta Nueva España. En la construcción de esta identidad legitimadora que propugna la propaganda de Franco, las referencias al pasado histórico serán una constante (Box 2008: 40-45). El régimen franquista buscará la continuidad efectiva, cronológica y simbólica con un pasado cuyos hitos -la reconquista, los Reyes Católicos, la Conquista de América, Felipe II, etc.- se mitifican y adquieren una relevancia máxima en el repertorio patrimonial. Para ello se utilizan conocidos mecanismos, como la invención de la tradición (Hobsbawm 1983: 46), y se ponen en marcha recursos como la inclusión en los monumentos antiguos de la huella del autoproclamado "caudillo", la creación de autorrepresentaciones del régimen utilizando el repertorio simbólico de las glorias del pasado (Ortiz 1998), el pluriempleo de ciertos símbolos del antiguo poder, como el yugo y las flechas, y la elección de algunos estilos arquitectónicos -los castillos medievales, el herreriano o el neoclásico- como paradigmas del espíritu nacional, cuya máxima representación -muestra del esplendor imperial al que el Nuevo Estado pretendía emular- es el Monasterio del Escorial (Llorente 1995).

Pero como elemento legitimador el folclore es incluso más importante que la propia historia, porque es capaz de proporcionar al sistema político una continuidad fundamental y atemporal, orgánica, más profunda que la que se obtiene de la historia. Así, el pueblo (siempre enunciado como el "pueblo español") es el referente máximo de todo el sistema político como detentador de las cualidades esenciales espirituales (el substrato de la "raza") con las que se identifica plenamente la ideología fascista del Movimiento. A partir de este principio, la cultura popular, es decir, las obras de ese pueblo, y en concreto ciertos elementos de tipo emotivo o estético (la música y la poesía, por ejemplo) tomados como acervo antiguo con el que es fácil identificarse, pueden ser utilizados para afianzar o establecer lazos de cohesión o pertenencia a ciertos grupos, reales o artificiales, y también en la socialización e inculcación de creencias, sistemas de valores o convenciones de comportamiento (Hobsbawm 1983: 19).

Esta idea esteticista y romántica de un pueblo idealizado, en el que residen los caracteres esenciales de una nación, y que no se divide en clases ni categorías económicas, es lo que resulta muy útil a la ideología nacionalista y fascista. $Y$ esto es así porque estos sistemas participan de un mecanismo general de la acción política que consiste en la apropiación, y dirección en un único sentido acorde con la ideología dominante, de los referentes étnicos o identificativos de cualquier población; y entre ellos destacaríamos por su importancia, la lengua, el traje, la arquitectura, la música y los rituales propios o característicos. El folclore en este sentido aparece como la forma más directa, más emotiva, de aprehensión del "estilo" de una comunidad y, por tanto, como un instrumento privilegiado de mediación entre la gente y la estructura política (Bausinger 1993: 68-71).

En la ideología franquista el asunto de la nación y su identidad, ligada a un fuerte centralismo estatal, es un elemento fundamental. La unidad de España es, tal vez, el objetivo político de mayor entidad en la retórica de la dictadura. La centralización de las funciones, desde las puramente políticas hasta las actividades más cotidianas, se establece a través de un sistema orgánico de relación sucesiva de distintos niveles de jerarquía que, desde la base más local, acaba siempre en la figura del jefe del Estado. El recurso a una teoría orgánica de la sociedad, radicalmente conservadora y arcaica, crea la superestructura en la que es posible absorber múltiples contradicciones (centro-periferia, lucha socioeconómica de clases, contraposición mundo campesino-industrial, etc.), mediante el recurso a la idea esencialista de la nación como una entidad primigenia y eterna.

En el discurso del régimen, la subversión de este principio de la unidad sagrada de la patria por los separatismos periféricos había llevado al caos, representado por la guerra. Por lo tanto, no solo era necesario impedir cualquier intento de rebrote del regionalismo en niveles muy elementales, sino que en su denigración se encontraba uno de los elementos más prácticos de cohesión del nuevo sistema 
estatal: a saber, el españolismo más extremo. Aquí, de nuevo, el folclore viene en ayuda de la ideología para salvar la contradicción entre una realidad que mostraba diferencias evidentes y la idea monolítica de un supuesto prístino, arcaico y único pueblo español. La solución encontrada es convertir el regionalismo en un elemento estético y emocional, con lo cual la diversidad regional pasa a ser un aspecto no problemático en la composición del cuadro general de la nación. Así pues, la diferencia regional se folcloriza: es decir, se resume en la expresión de pluralidad de dialectos (nunca lenguas), usos y costumbres, músicas, fiestas y trajes regionales, en los que se manifiesta verdaderamente el "pueblo español" (o su genio o su alma), sin más divisiones, o con tantas versiones locales que no es fácil encontrar la manifestación cultural concreta, adscrita a una comunidad histórica o culturalmente definida. Esta es la razón por la cual el franquismo insiste continuamente en el tópico de la variedad de formas de cultura tradicional que conviven en España y permite la expresión lingüística autóctona en las manifestaciones folclóricas (como reducto casi único), tanto en las publicaciones específicas, como en las exhibiciones públicas. Esto será un hecho en los trabajos de la propia Sección Femenina de Falange, expresado con palabras de Pilar Primo de Rivera: "Así, los catalanes cantaban en catalán; los vascos en vasco; los gallegos en gallego, en un reconocimiento de los valores específicos, pero todo ello y sólo en función de España y de su irrevocable unidad, dentro de la unidad peninsular" (en Casero 2000: 77).

Sin embargo, y sin que esto suponga contradicción, lo cierto es que para el franquismo España es Castilla, el castellano, lo castellano y los castellanos. No podía haber dudas sobre la primacía castellana en el dominio del resto de las regiones (a las que había sojuzgado históricamente) y sobre la identificación de la "hispanidad" con unos supuestos valores esenciales de Castilla. Así, por ejemplo, en la elección por Pilar Primo de Rivera del castillo de la Mota como sede central y símbolo de la organización femenina de la Falange, no solo pesaba la carga histórica y la figura femenina de la reina Isabel, sino también el castellanismo, la ruralidad (que hacía además contrapunto con una organización de origen y extracción eminentemente urbana y burguesa).

Si España es Castilla, Castilla es la representación más ideal del campo; el castellano es sinónimo de campesino y campesino lo es de español; por tanto, el identificador general último es el mundo campesino; evidentemente conceptuado de un modo esencial. El espíritu nacional, la hispanidad, la estirpe racial hispana, tenían su origen en el mundo agrario y en su cultura. $Y$ así era en sus útiles, su artesanía, su arquitectura, sus danzas y sus cantos, donde podía encontrarse la especificidad de la esencia nacional, sin contaminación externa alguna. En este esquema, los campesinos -su presentación idealizada- funcionaban como un mito, no eran reales, sino que proporcionaban al resto de la población un referente de origen, de carácter emocional, no lógico: todos, independientemente de las diferencias sociales efectivas, procedían de los mismos orígenes. El sustrato nacional campesino era la base de un edificio social, supuestamente "natural". De esta manera el régimen político obtenía una legitimidad aparente, para sus actos coercitivos y su estructura, al estar fundado en algo eterno, inmutable, justo y, por tanto, muy difícil de rechazar (Bausinger 1993: 73-74). De la misma forma que el regionalismo folclorista se utiliza para negar la posibilidad de un conflicto cultural entre las distintas nacionalidades históricas existentes en España, la utilización en la escenografía del régimen de una estética basada en ciertos valores étnicos y culturales idealizados del campo pone de manifiesto, de una forma más cruda aún si cabe, la contradicción con una realidad marcada, sobre todo durante los años de la durísima postguerra, por una crisis agraria absoluta y el mantenimiento de unos indicadores de nivel de vida de miseria para los agricultores, que desembocarán, a partir de los años cincuenta, en la expulsión masiva de buena parte del contingente de habitantes del mundo rural hacia las ciudades y los países industriales.

A pesar de todo, la aparición pública de una imagen bucólica campesina, como símbolo de la unidad que se pretendía construir sobre la variedad casticista y folclórica, es frecuente en las celebraciones de las efemérides instauradas o revalorizadas por el franquismo. Una de las primeras concentraciones, fue el homenaje al "Caudillo y al Ejército de la Victoria" que Pilar Primo de Rivera, al frente de la Sección Femenina de Falange, organizó en el Castillo de la Mota, en Medina del Campo, el 30 de mayo de 1939. En esta temprana celebración aparece ya el que será el modelo de representación oficial de la Sección Femenina de Falange. El programa de actos ( $A B C$ 30-5-1939: 10) constaba de tres partes: Ios discursos falangistas, una exhibición folclórica y gimnástica, y la ofrenda al Generalísimo de los frutos de la tierra, 
de manos de veinticinco campesinas jóvenes, pertenecientes a la Hermandad de la Ciudad y el Campo, procedentes de las distintas provincias y ataviadas con sus respectivos trajes regionales (Suárez Fernández 1993: 99-100). El espectáculo masivo organizado por la Sección Femenina incluyó un coro de 2.090 voces, dirigido por el maestro Rafael Benedito, que interpretó una selección de canciones regionales de España, acompañadas por sus bailes típicos (Casero 2000: 44).

\section{La Sección Femenina de Falange Española y de las Juntas de Ofensiva Nacional Sindicalista}

La Sección Femenina del que se ha considerado como el primer partido puro fascista de nuestro país, nació prácticamente con la propia Falange, ya que el 15 de febrero de 1934 se firma el acuerdo entre Falange Española y las JONS, y en junio de 1934 nace su llamada Sección Femenina (su primer Estatuto lo firmará José Antonio en diciembre) (Casero 2000: 15). Cuando se disolvió el 1 de abril de 1977, con el decreto que suprimía la estructura de la Secretaría General del Movimiento (Fernández Jiménez 2008: 332-340), podía ser considerada una de las instituciones más longevas del franquismo y su dirigente máxima, la hermana del héroe fundador José Antonio, Pilar Primo de Rivera, seguramente la persona, junto a Franco, que más tiempo desempeñó un puesto político de ámbito nacional en la dictadura. Desde el comienzo, se manifiesta como una organización eminentemente política (Ofer 2009), cuyo objetivo es contribuir "al duro propósito de hacer una España más grande y más justa". En el Primer manifiesto de la S. F. de 1934 se declara también su posición meramente auxiliar de los hombres en estas tareas políticas y su misión encaminada a mantener los valores y los principios de lo que se consideraba por el régimen el papel fundamental de las mujeres, como madres (lo que paradójicamente ellas nunca serán) y como esposas (Richmond 2004). La referencia a la Sección Femenina, comúnmente siempre hecha así, sin aludir al partido fascista del que era parte, es una perfecta metáfora de su acción política: las mujeres no debían tener protagonismo en la política, ni en los asuntos públicos. Así, ellas -la parte femeninapretendían ser vistas socialmente, no tanto como miembros del partido único, como en cuanto representación y garantía del ideal (¿único?) de mujer que la dictadura promovía (Domingo 2007: 37-50).

Desde su origen como grupo de mujeres de apoyo en las acciones de los militantes falangistas, la organización creció y fue promocionada y utilizada por el régimen de Franco, consiguiendo amplias parcelas de poder en las que pudo desarrollar su acción sin la competencia de ninguna otra organización ni instancia, siempre que se mantuviera acorde a los principios del movimiento y no pretendiera salirse del marco estrictamente "femenino" que se había marcado desde un principio, como así fue. Sin embargo, que se tratara de una organización segregada y a la que se mantuvo en funciones relativamente subalternas que, además con el paso de las décadas fueron resultando cada vez más burocráticas y obsoletas, no debe hacer olvidar que la Sección Femenina fue una institución de control poderosa, cuyas funciones de enseñanza y de intervención en el ámbito doméstico la introdujeron de manera forzosa en la vida cotidiana de millones de mujeres durante el franquismo. Así, a las más de 600.000 afiliadas que llegó a tener en su momento álgido, habría que sumar a más de tres millones de mujeres que tuvieron que someterse a sus cuadros para cumplir con el Servicio Social Obligatorio (Alpuente 2009: 15, Rodríguez López 2010: 154-162).

Las tareas a que se dedicó con ahínco la Sección Femenina fueron variadas, y especialmente tuvieron que ver con el aparato de educación, tanto en lo que se refiere a la propaganda y a la educación paralela (es decir, externa a las instituciones educativas propiamente dichas, integradas en el sistema nacional de enseñanza: colegios, institutos, universidad), como a la propagación de un modelo femenino acorde con los principios del régimen y la religión católica (Otero 1999). A su vez, estuvo también encargada de misiones de control y vigilancia social, en los mismos aspectos que tocaban al desempeño satisfactorio de los papeles femeninos; esto es en todo lo que tenía que ver con la maternidad, incluida la salud física o deportiva de las mujeres que se consideraba adecuada para conseguir una buena salud reproductora (Manrique Arribas 2010). Un tercer sector en que tuvo protagonismo fue el de la organización y la higiene familiar, y el mantenimiento de las condiciones mínimas de una economía doméstica campesina en los hogares rurales (Pérez Moreno 2004; Marías Cadenas 2011). Finalmente, el recurso a la Sección Femenina en lo que tenía que ver con la propaganda política del régimen, tanto en el interior como en el 
exterior, y su intervención en la reglamentación del tiempo de ocio y en los rituales y puestas en escena durante todo el franquismo, a través de los Coros y Danzas y otras iniciativas, es otro de los sectores importantes en la organización (Casero 2000).

Para cumplir su tarea en estos terrenos, la Sección Femenina, cuya dirección fue ejercida durante toda su historia por una sola persona, Pilar Primo de Rivera (Fernández Jiménez 2008), como Delegada Nacional, se organizaba en regidurías, que inicialmente fueron cinco: Hermandad de la Ciudad y el Campo, Enfermeras, Cultura y Formación de Jerarquías, Cultura Física y Sindicatos, que se fueron complicando con una red de delegaciones provinciales y subdelegaciones específicas (Casero 2000: 2032). En ellas, se centralizaban las tareas de educación general y propaganda, formación de mandos, publicaciones, cursos, actuaciones públicas, y campañas de intervención por toda España. Sin embargo, no debe perderse de vista que todas sus funciones específicas, como la labor sanitaria, la vigilancia de la crianza de los niños, la actividad deportiva, la promoción de las artesanías, el folclore, etc., fueron siempre, pero sobre todo entre 1939 y 1960, tareas supeditadas a las funciones políticas.

Así, todas sus iniciativas en torno a la formación de las madres y de personal técnico especializado en puericultura estaban determinadas por una de las preocupaciones mayores del régimen franquista: el problema demográfico acuciante, producido por la sangría de la guerra y por una bajísima natalidad en la postguerra, agravada por un índice insoportable de mortalidad infantil y unos niveles de nutrición paupérrimos en madres y niños: las campañas en pro de la lactancia materna son un ejemplo en este sentido (Roca 1996). La actividad conocida de la Sección Femenina en la elaboración de canastillas para los recién nacidos sería otro caso de intento de mejora de las condiciones de salubridad e higiene en la crianza que las señoritas de la Sección Femenina, casi todas ellas solteras, extendían como un apostolado por los pueblos y aldeas españolas. Los cursos de economía doméstica, sus cursos y manuales de cocina y sus exposiciones de artesanía muestran los mismos objetivos de dirigir y encaminar las conductas domésticas y las actividades de las mujeres hacia formas útiles para la nación y para el Estado, por más que la ideología básica de supeditación de las mujeres al ámbito privado y a labores exclusivas de crianza y cuidado, lastrara cualquier intento realista de que lo enseñado por la Sección Femenina sirviera fuera de estos ámbitos.

\section{La obra folclórica de la Sección Femenina}

A pesar de que ya desde los años veinte había en España algunas instituciones y centros dedicados al estudio del folclore y la cultura tradicional, a diferencia del régimen nazi, el franquismo no encargará de esta labor a un centro de estudios oficial ni a profesionales especializados. Utilizará a la Sección Femenina de Falange para cumplir con esta misión (Berlanga 2001) que, como el resto de las desempeñadas por ella, será una mezcla de enseñanza paralela y acción política dedicada a los objetivos de organización de espectáculos, ocio y propaganda del Estado, y en último término una manera de mantener a las mujeres alejadas de los niveles superiores de educación y profesionalismo, y ocupadas en actividades consideradas "femeninas"; es decir, inocuas, blandas, estéticas y emotivas. En esta obra de investigación, exaltación y folclorización de las manifestaciones de la cultura popular (en la que contará con la colaboración de algunos musicólogos y especialistas, como Rafael Benedito, Manuel García Matos o el propio Ramón Menéndez Pidal), la Sección Femenina se centrará en los aspectos más estéticos y capaces de producir tipismo (como el llamado traje regional) y en los emotivos y sensibles (como la música y la danza).

Se ha señalado que el primer objetivo temático de la obra folklórica de la Sección Femenina fue la música, como resulta evidente con la organización de los cursos de instructoras de música en 1938 (Casero 2000: 40), dirigidos por el maestro Benedito, que será el asesor musical de las falangistas en su primera época. De hecho, el Departamento de Música será siempre uno de los más importantes de la Regiduría de Cultura, sobre la base de que la música popular española (junto con la sacra y litúrgica) era un elemento de primer orden para canalizar la sensibilidad y la emocionalidad de la gente en un sentido "nacional". Después de la guerra habían quedado prohibidos el jazz y otros géneros populares de origen 
foráneo (Ferrer Senabre 2011: 3) y se privilegiaba la zarzuela y algunas otras músicas, como la copla, hasta el punto de que quedarán en la memoria de los españoles indisolublemente ligadas al franquismo.

Tanto en lo que se refiere a la investigación musical como en la que tiene que ver con la indumentaria que se llevó a cabo en la Sección Femenina, el punto de partida era el respeto o la reivindicación de la "tradición". Sin embargo, esta tradición debía ser rescatada del abandono en que había estado (evidentemente se hace referencia con esto a los tiempos republicanos), como si hubiera sido necesario llegar a esa conciencia "metafísica" de la nación y su destino, que propugnada el fundador de Falange, para descubrir y hacer vivir esos rasgos de la raza hispánica, ya presentes en los tiempos primigenios y latentes en el pueblo sencillo, pero que estaban al borde del olvido y la extinción. En palabras de la que será durante muchísimos años regidora de Cultura, María Josefa Sampelayo: "En la España del año 36, estas manifestaciones folklóricas habían prácticamente desaparecido [...] aún lo poco que quedaba perdía a pasos agigantados su sabor [...]. El gran acierto de la S. F. fue el saber ver y valorar aquel tesoro inmenso y todavía recuperable" (Sampelayo 1969: 99).

Es decir, se procura alguna instancia para recrear lo que, políticamente es necesario y cómo es necesario. Para que, finalmente, el producto debidamente reelaborado, se vuelva a ofrecer al pueblo como un espectáculo edificante (que, de paso, contrarresta, la posibilidad de introducción de otras músicas y bailes peligrosos, por su procedencia extranjera y su supuesta inmoralidad). Así se organizan las exhibiciones masivas que prácticamente desde 1939 protagoniza de forma ininterrumpida la Sección Femenina por todo el país, a través de sus concursos y sobre todo de los Coros y Danzas de España, en lo que ellas mismas denominarán una "estupenda labor política" (Sampelayo 1969: 100).

Pasando por ese control desde arriba, la cultura surgida del pueblo, volvía al pueblo. Pero además, esa imagen folclórica, típica y bucólica del enorme y variado acervo de nuestra cultura popular pasará de ser un elemento de propaganda interna a proporcionar también más adelante una imagen amable del régimen en el exterior. Como lo explicó Luis Suárez Fernández en su crónica de la Sección Femenina:

"El mundo, en cuanto a música se refiere, no conocía a España casi nada más que por una deformación de lo andaluz [...]. Los mismos españoles, quitando algunos pueblos, que tuvieron siempre una preocupación mayor por sus tradiciones, habían olvidado que en la entraña de la tierra tenían la mayor riqueza folklórica del orbe. Y tuvo que venir la Sección Femenina, con todo el vigor de sus juventudes y toda su voluntad falangista, a desenterrar pueblo por pueblo la canción y la danza, que en muchos sitios ya solo se conservaba en la mente de los viejos. Y a fuerza de concursos y a fuerza de estímulos volver a la vida el tesoro incomparable de nuestro arte popular, con toda su variedad de danzas religiosas y guerreras, cortesanas y pastoriles, de menestrales y de enamorados" (Suárez 1993: 209).

Es evidente que la Sección Femenina no fue la primera ni la única institución que utilizó la imagen del exotismo o el color local representado por los campesinos en los espectáculos y ceremoniales de las elites políticas. Sin embargo, lo cierto es que el régimen utilizó enseguida la labor de la Sección Femenina en su vertiente de espectáculo. Ya se mencionó su aparición en primer plano en el espectáculo que tuvo lugar el 30 de mayo de 1939 en Medina del Campo, en el castillo de la Mota, para homenajear a Franco y los vencedores. En 1940, para celebrar el primer aniversario del final de la guerra, la Regidora de Cultura de Madrid, $\mathrm{M}^{\mathrm{a}}$ Josefa Sampelayo propuso que las afiliadas bailasen y cantasen en las plazas de todos los pueblos (Casero 2000: 47).

En este contexto, se pone en marcha el que será mayor éxito de toda la organización de la Sección Femenina, el Concurso Nacional de Coros y Danzas de España, cuya primera edición tiene lugar ya en 1941-1942, a iniciativa de la propia Pilar Primo de Rivera. A partir de la música y la creación de coros, muy pronto las instructoras de música ampliaron el repertorio a las danzas, que presentaban mucha mayor capacidad de espectáculo y en las que tendrán los trajes una posición muy importante. El primer concurso de Coros y Danzas se inició el 27 de febrero de 1942 y terminó en julio de ese año. El sistema de competición tenía un nivel provincial, en el que participaban los grupos locales. El grupo vencedor de cada provincia pasaba a competir a nivel regional, de ahí pasaban a uno de los cuatro sectores en que se 
había dividido el territorio nacional y, por último, los ganadores participaban en el certamen nacional, que se celebraba en Madrid. El concurso se dividía en tres apartados: de Coros, de Danzas y grupos mixtos (presentaban danzas y canciones conjuntamente) y en él se valoraba también la indumentaria de los grupos. El concurso se mantuvo desde 1942, hasta 1976 en que se celebró el último; es decir, en total hubo 20 ediciones nacionales, pudiendo decirse que la época dorada de los coros y danzas, en que hubo mayor incremento de grupos y espectáculos abarca entre 1948 y 1962 (Casero 2000: 48-49).

En los primeros años, evidentemente no había ninguna posibilidad de proyección exterior, excepto un viaje a Alemania que tiene lugar en 1942 para visitar a los soldados de la División Azul (Casero 2000: 49). Pero la visita de Eva Perón a España en 1947 va a cambiar esta situación y a partir de ella se producen diversas iniciativas para que los Coros y Danzas y la Sección Femenina sirvan como una especie de embajada cultural del franquismo en varios países latinoamericanos, y más tarde por Europa y los Estados Unidos en los años 60. El primer viaje, la expedición que partió el 17 de abril de 1948 a bordo del buque Monte Albertia rumbo a Argentina, fue un éxito diplomático y también de público, y fue seguido de una nueva gira por Panamá, Ecuador y Colombia que aparece reseñada en la película Ronda Española de Ladislao Vajda estrenada en Madrid en 1951 (cf. Suárez 1993: 215-239).

En los Coros y Danzas, sus concursos y exhibiciones, aparece un espectáculo folclórico reconstruido, en el cual la mediación de las instructoras de la Sección Femenina tenía un papel fundamental, dado que la recogida de la información en los pueblos y la instrucción de los grupos locales dependía de unas normas y unas técnicas que no tenían nada que ver con el mantenimiento de las costumbres y los estilos tradicionales de tipo local. Bien al contrario, como puede verse en las fichas que las instructoras debían enviar a la Regiduría Central de Cultura en Madrid (Casero 2000: 12-13), la indeterminación en la recogida de los datos, por un lado, y, por otro, la homologación de las muestras de música y las danzas a patrones estandarizados es la norma. A esto habría que unir la dedicación amateur de las afiliadas y la falta general de medios técnicos para el trabajo de recopilación (ver una descripción pormenorizada, incluyendo testimonios directos, de este proceso en Casero 2000: 83-103). Con todo, se procuraba también mantener el "prestigio" de la labor folclórica, por ejemplo, invitando a Ramón Menéndez Pidal a escribir el prólogo para el libro Canciones y danzas de España (1953) o mediante la constitución, a través de la Vicesecretaría de Educación Popular del Ministerio de Educación, del Premio Nacional de Folclore, cuya primera edición, en 1945, recayó en Manuel García Matos. La propia Sección Femenina, en este como en los otros ámbitos de su actividad, reunía en sí misma el control absoluto de las tres funciones de su labor: recuperación, enseñanza y difusión. En lo que tiene que ver con el trabajo folclórico, creó un cuerpo de Instructoras de Bailes Regionales y Música, que eran formadas, con los propios textos y métodos publicados por la organización, en sus Escuelas Nacionales y Provinciales de Mandos. Pero, además, hay otros elementos que inevitablemente llevaron a la mistificación y falseamiento de los estilos folclóricos originales.

El primero es de carácter moral y conllevaba la censura de cualquier elemento cultural o formal que no estuviera acorde con la ideología nacional-católica. Así fueron cambiadas las letras anticlericales o antirreligiosas de las canciones, o tenemos que hasta 1957 todas las danzas eran interpretadas únicamente por mujeres, aunque se tratara de bailes mixtos en su inmensa mayoría (Casero 2000: 97). En lo que respecta a la indumentaria de los trajes regionales que se lucían en los bailes, por ejemplo, y a decir de las propias afiliadas y participantes en los Coros y Danzas, los trajes incluían como prenda tradicional interior los famosos pololos o pantaloncillos recogidos en la pierna, que era obligatorio igualmente llevar bajo las faldas en la práctica deportiva. Otros cambios marcados por la decencia indumentaria fueron aplicados a escotes y largura de las mangas en varios casos y a la propia interpretación de las danzas.

Igualmente importante, es la norma obligatoria de que los grupos y los coros debían dedicarse al aprendizaje y práctica de los repertorios de su respectiva "provincia", de manera que se confunde constantemente el carácter local de muchas manifestaciones, sean danzas o trajes o canciones, con su asimilación provincial y si es el caso regional. Así, el llamado traje regional no es sino una recopilación selectiva de trajes locales, que se extienden a un ámbito comarcal (como en el caso del traje regional de Valencia, dividido en dos facies, "de Ribera" y "de Montaña". Cf. Añón y Montoliu 2011: 23) o 
preferentemente provincial y de ahí obtienen representatividad regional: el traje de charra de Salamanca, el extremeño, procedente de Montehermoso (Cáceres), o el de "maga" canaria pueden ser ejemplos representativos de esta mixtificación.

En definitiva, y aparte del fundamental elemento ideológico, que ya se ha comentado, dos problemas teóricos fundamentales lastraron todo el proceso de recopilación, estudio y difusión del folclore español llevado a cabo por la Sección Femenina. En principio, la escasa preparación y rigor con que la labor se realizó (Casero 2000: 92-93), con una absoluta falta de criterios generales, protocolos estandarizados y formación técnica básica del personal encargado de la recogida de datos en las comunidades locales. Pero, aún más importante, por su trascendencia, fue la extensión de un folclore "reconstruido" por toda España. Los repertorios locales, provinciales y regionales, que debían ser "típicos" y que se elaboraban siguiendo las normas que las instructoras habían recibido en sus cursos de música y folclore, eran a su vez, enseñados a los coros, comparsas y grupos de intérpretes locales de toda España por medio de las mismas instructoras y de las Cátedras Ambulantes que la Sección Femenina repartía por todo el territorio nacional para impartir sus cursos y enseñanzas domésticas (Lizarazu 1996), pero también a través del aprendizaje de los "bailes regionales" en las Escuelas Normales y los Institutos de Secundaria (Añón y Montolíu 2011: 11). De manera que, si el sistema que se empleaba para recopilar las manifestaciones artísticas "auténticas" de los pueblos creaba un folclore mistificado y distorsionado; este fue, a su vez, el producto que se reprodujo a través del tiempo, aprendido y repetido por los actores locales en sus repertorios y actuaciones hasta el día de hoy.

\section{El tratamiento "cultural" de los trajes regionales}

Nos introducimos así en el asunto de la construcción cultural de los trajes regionales españoles por la Sección Femenina. Es evidente que la construcción de la indumentaria llamada popular en España no comienza ni acaba con la Sección Femenina (Valadés 1994). La época dorada en la que se crea la idea de que en España el pueblo viste de un modo artístico, propio, antiguo y espectacularmente rico y variado, podría situarse entre la colección de grabados representando trajes de Juan de la Cruz Cano y Olmedilla (1777) y las fotografías de España. Tipos y Trajes, de José Ortiz Echagüe (1930) (Vega 2005: 63). Las estampas de Cano y Olmedilla enseñaban un abanico rico y variado de tipos populares cuyo sabor local radicaba en su indumentaria. A partir de mitad del siglo XIX comienza a difundirse el discurso que establece que la modernización conlleva la desaparición inexorable del traje de los "reinos" de España y su sustitución o rescate, y su conversión en traje "pintoresco", "popular", "regional", "provincial" y finalmente "tradicional" (Vega 2005: 70; Cea y otros 1986).

La aparición de las comparsas costeadas por las provincias que desfilaron en Madrid con motivo de las fiestas por la boda del rey Alfonso XII y María de las Mercedes, en enero de 1878, en las cuales las parejas iban ataviadas con los trajes típicos, danzaban y cantaban por las calles, despertó un interés muy grande y nos ha llegado en alguna forma congelada por el objetivo del fotógrafo Laurent. 


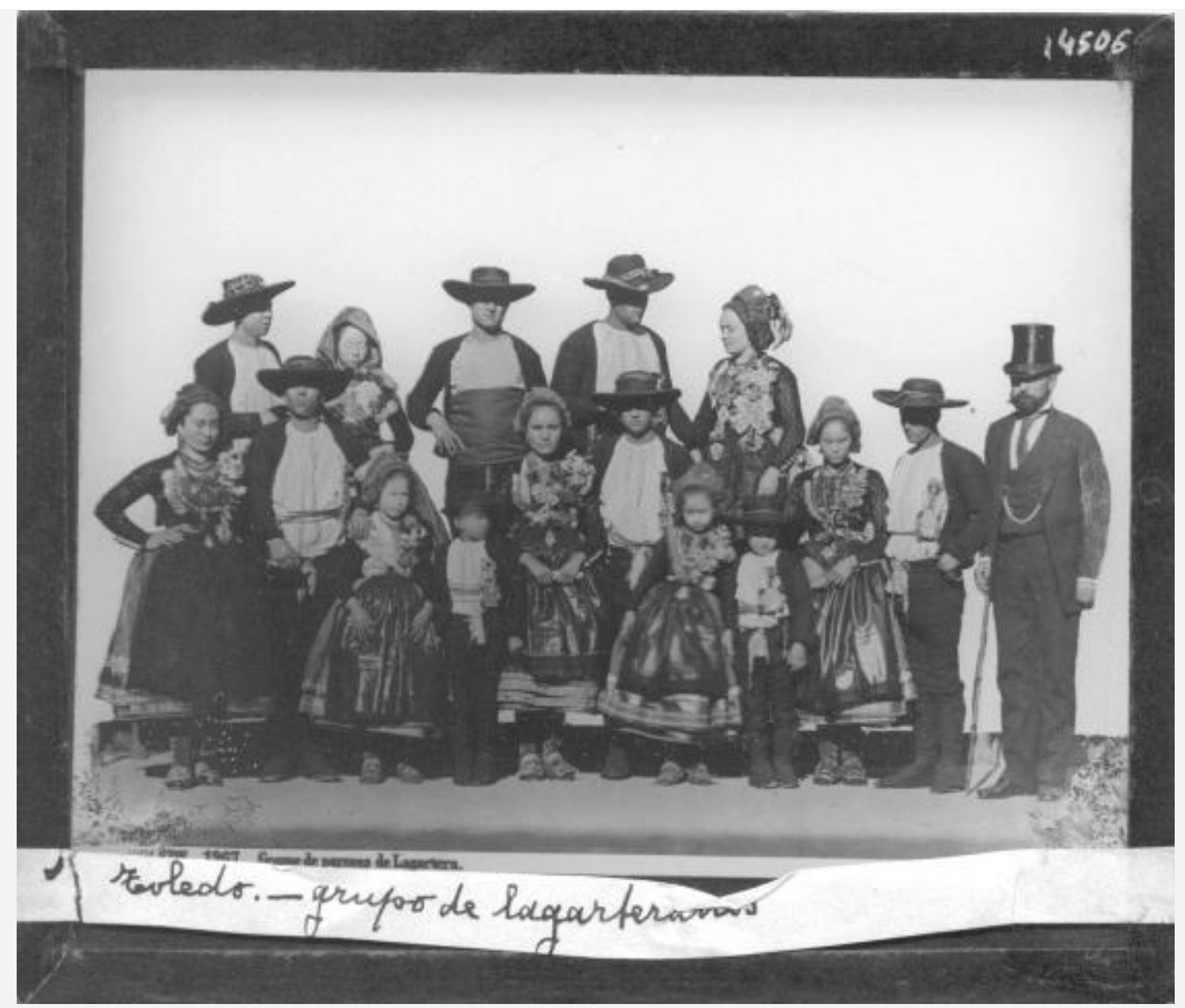

Figura 1. Grupo de Lagarteranos. Comparsa de Toledo. Madrid, 1878. Fotografía de Laurent. Escuela Superior del Magisterio. Madrid.

La internacionalmente conocida obra de Sorolla "Visión de España", encargada en 1911 para la Hispanic Society de Nueva York y compuesta por un mural de catorce lienzos, resuelve la representación de España y su historia a través de la localización de figuras humanas enraizadas en su identidad, utilizando como recurso en los distintos cuadros su ubicación en un territorio plenamente reconocible, y manteniendo una actitud que se identifica culturalmente, gracias a la representación de las fiestas y los trajes característicos. Finalmente, durante los años veinte y treinta, la construcción artística de la obra del fotógrafo pictorialista José Ortiz Echagüe (Vega 2002), estableciendo tipos esenciales, aislados, inalterados, más allá de la realidad y el tiempo, crea un estereotipo y hasta un mito, porque retrata con técnicas fotográficas una realidad construida y ya inexistente. Más bien lo que fotografía es la pérdida, la ausencia de ese español detentador de un supuesto carácter prístino y ancestral. Esta imagen, perfectamente coherente con la ideología nacional-católica, obtendrá un éxito total en la estética franquista. 


\section{COSTUMES}

PAINTED BY SOROLLA IN HIS PROVINCES OF SPAIN

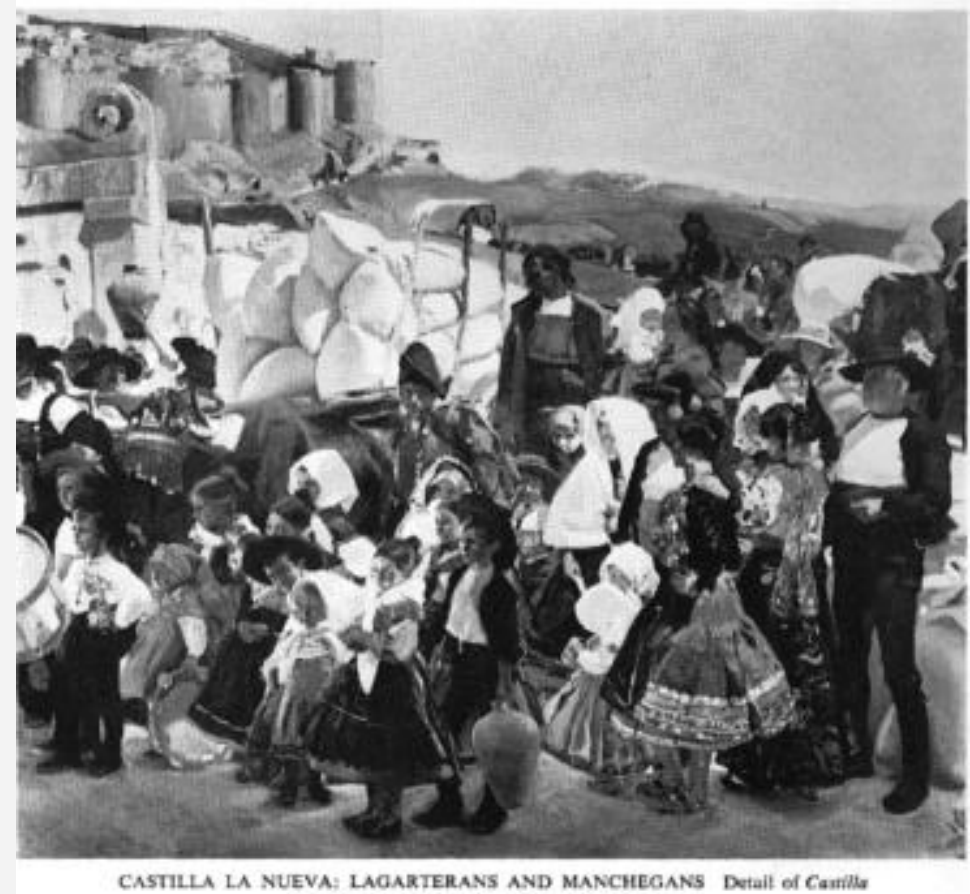
The Hisponic Saciety of Americe. Sarolla Reom

By RUTH MATILDA ANDERSON

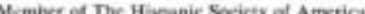

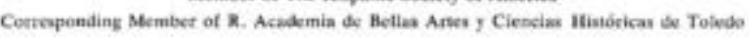

Price: $\$ 4,00$

Figura 2. Anuncio del libro de R. M. Anderson sobre "Visión de España" de Sorolla. Nueva York, Hispanic Society of America, 1957.

En la postguerra tenemos otros ejemplos de esta misma representación arcaizante, exótica y "étnica". Así, contamos con el testimonio gráfico de un fotógrafo local del "desfile regional" que se organizó en León el 21 de mayo de 1939 para celebrar el triunfo del General Franco y "agradecer a la Legión Cóndor alemana su presencia en León y ayuda durante la contienda" (Sutil 1997: 11), en el que deambularon y bailaron por las calles 4.600 personas vestidas con sus trajes típicos, venidas de las comarcas de la Maragatería, Ribera del Órbigo, Páramo, Montaña, etc. Estas "fiestas regionales de la Victoria" conllevaron una serie de premios en metálico para los grupos, coros y personas más representativas y mejor vestidas (los trofeos de la Victoria). Con motivo de la entrega de estos premios, se repitieron los desfiles en la ciudad de Astorga en junio de 1939 (Sutil 1997: 59) y, posteriormente, de nuevo se hicieron en León en julio de 1941. 


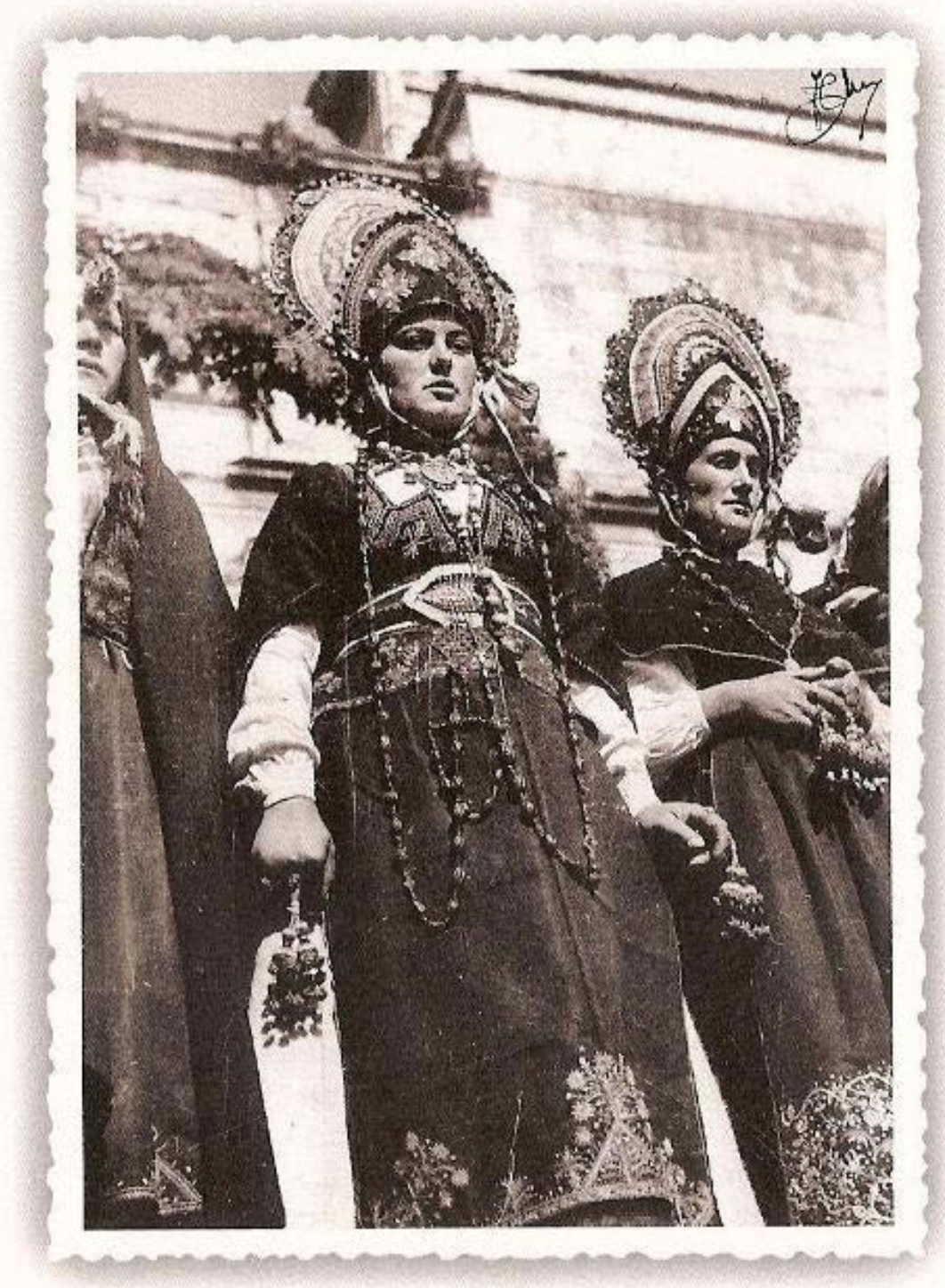

Figura 3. Jóvenes maragatas, ataviadas con el traje "antiguo". Plaza Mayor de Astorga, 11 de junio de 1939. Fotografía de Martín Prado. Tomada de Sutil 1997, p. 56.

Paralelamente, durante el primer tercio del siglo XX, desde el ámbito de la investigación folclórica se va conformando un corpus de materiales elaborados y de colecciones sobre la indumentaria tradicional española que configura en una parte no desdeñable lo que sabemos hoy en día sobre este tema. Así, a partir de las enseñanzas de Luis de Hoyos en la Escuela de Estudios Superiores del Magisterio que comienzan en la década de 1910, se producirá el primer acopio de datos obtenidos sobre el terreno acerca de la variedad de trajes populares en el ámbito nacional (Ortiz 1988). En el seminario de etnografía y en el de labores mantenidos en la Escuela Superior del Magisterio en Madrid, se llevarán a cabo una serie de memorias de investigación de fin de carrera que tendrán como objeto la indumentaria tradicional de distintas localidades y áreas, y que aportarán por primera vez documentación fotográfica, patrones y dibujos de las prendas, muestras de tejidos y materiales, terminología propia, etc. 

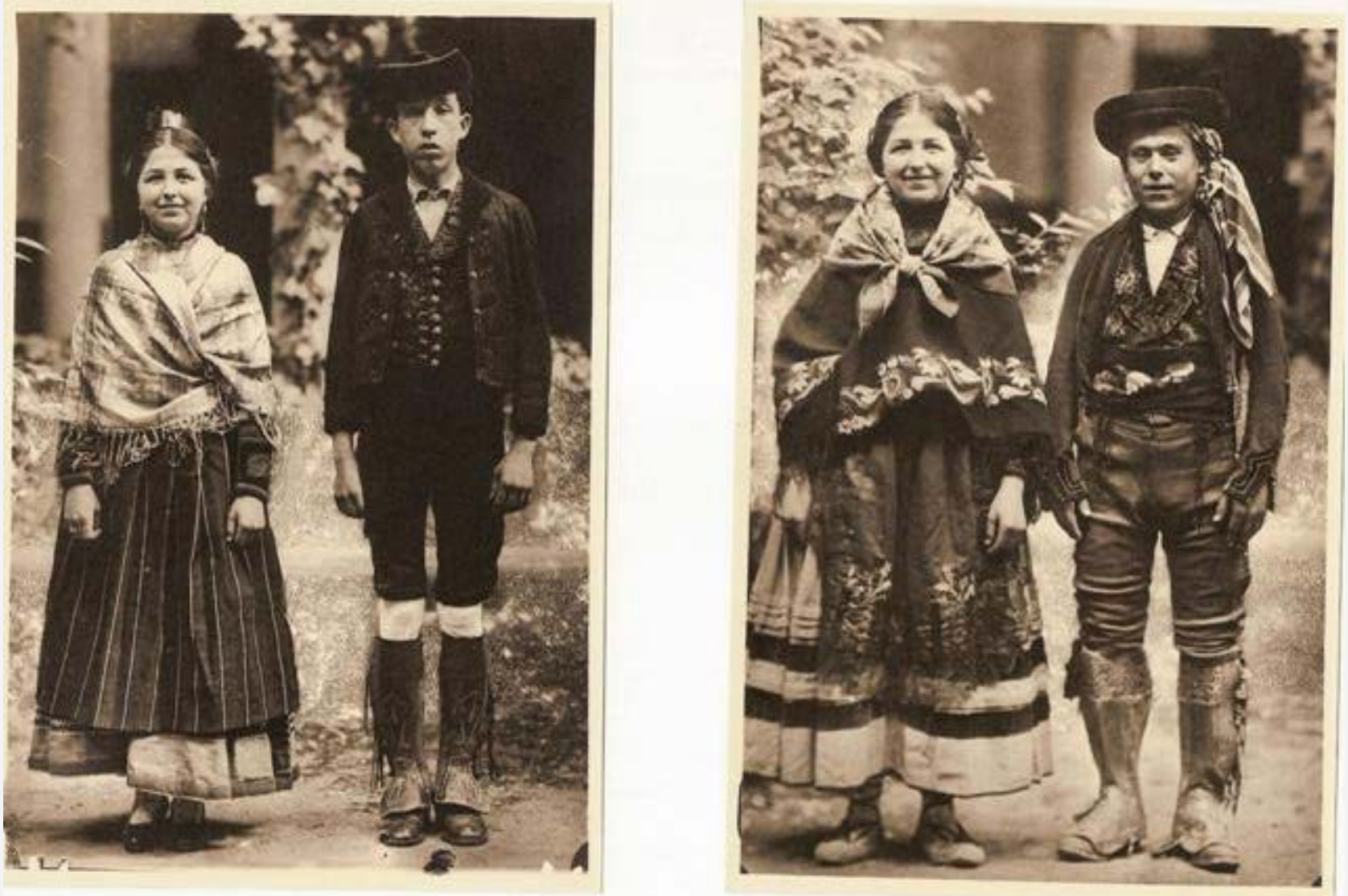

Figura 4. Parejas con trajes de Pontones y Quesada (Jaén). Escuela Superior del Magisterio. Madrid.

Esta labor de Luis de Hoyos y sus colaboradoras culminará en la Exposición del Traje Regional Español en 1925 y en la creación del primer Museo del Traje, antecedente del Museo del Pueblo Español (posteriormente convertido de nuevo en el actual Museo del Traje).
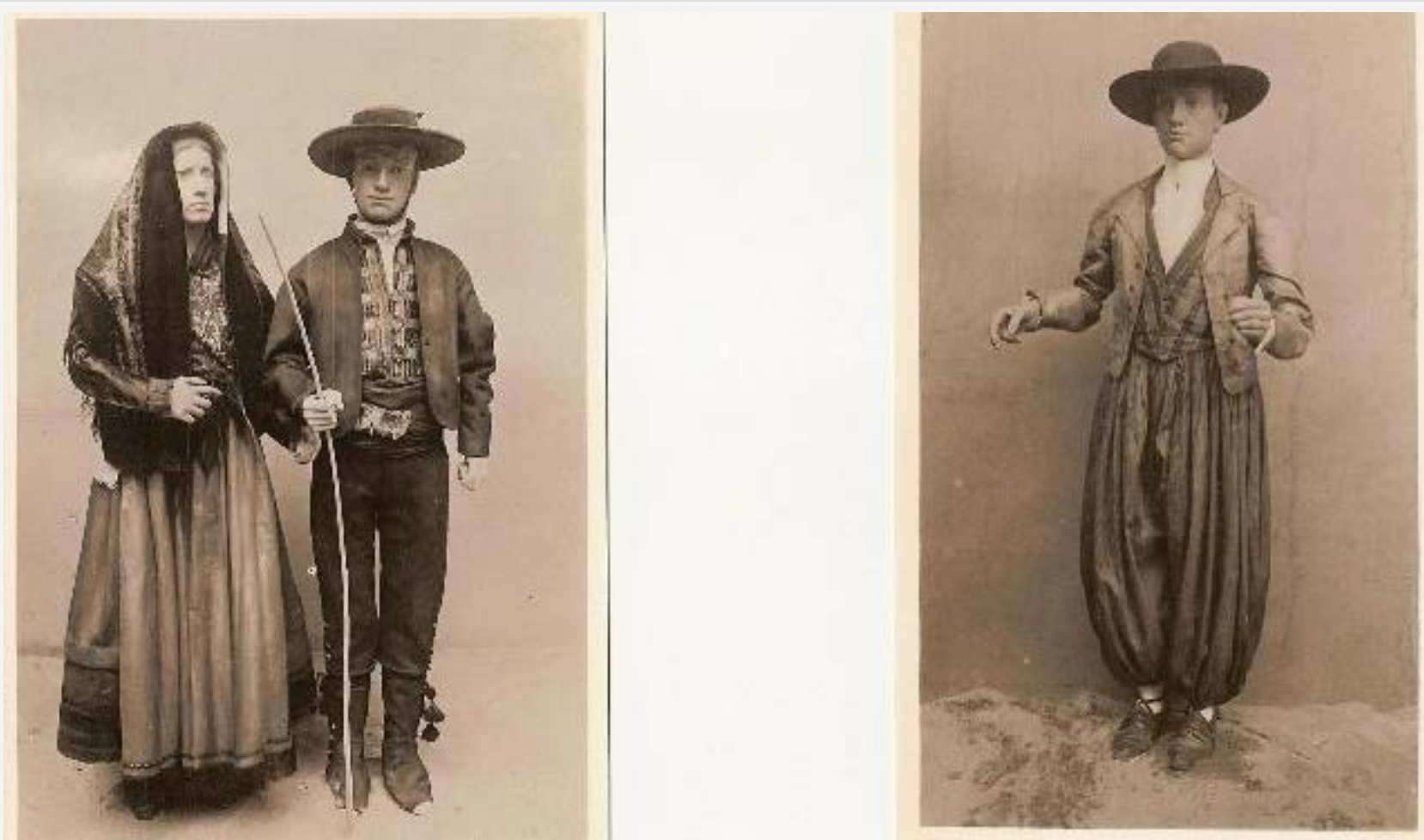

Figura 5. Trajes de El Barraco (Ávila) y Mallorca. Exposición del Traje. Madrid, 1925. Fotografía Artística de Antonio Prats. Madrid. 
Después de la guerra, el Museo del Pueblo Español -una fundación institucional del gobierno de la República- seguirá avatares diversos, pero sin llegar a lograr por un tiempo duradero la exposición de sus colecciones, y será la Sección Femenina de Falange, en el contexto de sus otras actividades formativas y de espectáculo, la que continuará con la tarea de construir y mantener el objeto complejo de los trajes regionales españoles. De hecho, buena parte de los trajes elaborados durante el franquismo tuvieron como modelos aquellos locales o regionales tipificados antes por los museos o las organizaciones dedicadas a la investigación etnográfica regional, donde las había (Carretero 2004). Con todo, estas instituciones actuaban conforme a una metodología en la que la mistificación y la intervención eran también la norma. Podemos juzgar la manera de proceder, a través de las palabras de una de las especialistas en el estudio del traje regional español, Nieves de Hoyos Sancho, que se refiere a la configuración de los trajes provenientes del País Vasco para el Museo del Pueblo Español:

"De Vizcaya, en el año 1936 se consiguieron bastantes prendas, esencialmente en Dima. Con ellas pueden vestirse una pareja, pero son trajes casi totalmente negros, con telas empobrecidas por el uso que dan una idea triste [...]. Encontrar trajes auténticos resulta imposible [...] entablamos relación con Karmele Goñi de Múgica [...]. Hablando con todos los viejos y viejas encontró algunas prendas. Con esta directa documentación ha hecho dos trajes de aldeanos, con linos caseros, cuerdas tejidas por algunos pastores, tejidos en general auténticos [...]" (Hoyos 1971: 525).

Es evidente que la Sección Femenina contó en su tarea con el conocimiento de muchas expertas, las colecciones de trajes y todo el material acumulado anteriormente, y también hizo contribuciones en el terreno de la documentación etnográfica, ampliando su inicial interés por la música y la danza, a los trajes, la culinaria popular y otras artesanías; temas que se pensaba investigar en un proyectado Instituto de Folclore que María Josefa Sampelayo y Manuel García Matos pensaban poner en marcha en 1966 y que no se llegó a materializar. Al final, la inmensa tarea de recopilación de danzas y música hecha por los pueblos, que según los datos de Estrella Casero (2000: 91) había acumulado en la Regiduría Central de Cultura 1.068 fichas de danzas se desperdigó después de la disolución de la Sección Femenina, en manos de particulares y de los grupos herederos de la organización falangista (Primo de Rivera 1983: 69), como la Asociación Nueva Andadura, la Asociación de Antiguos Componentes de Coros y Danzas, presidida por Amparo Añón Baylach en Valencia o la Federación de Asociaciones de Coros y Danzas de España que creó la propia Maruja Sampelayo.

Igual que se había hecho con los cancioneros y con la cocina se editaron algunas publicaciones sobre los trajes, como un libro, publicado en 1966, en el que se recogían cien trajes típicos y que se pensó como una guía para mantener la "autenticidad" de los vestidos que se fabricaban para ser utilizados por los grupos de los Coros y Danzas (Casero 2000: 54). Esta estandarización propuesta en el modelo del traje regional por la Sección Femenina se divulgó a través de la famosa serie de sellos de correos, con los trajes regionales de España, editada a partir de 1967. 


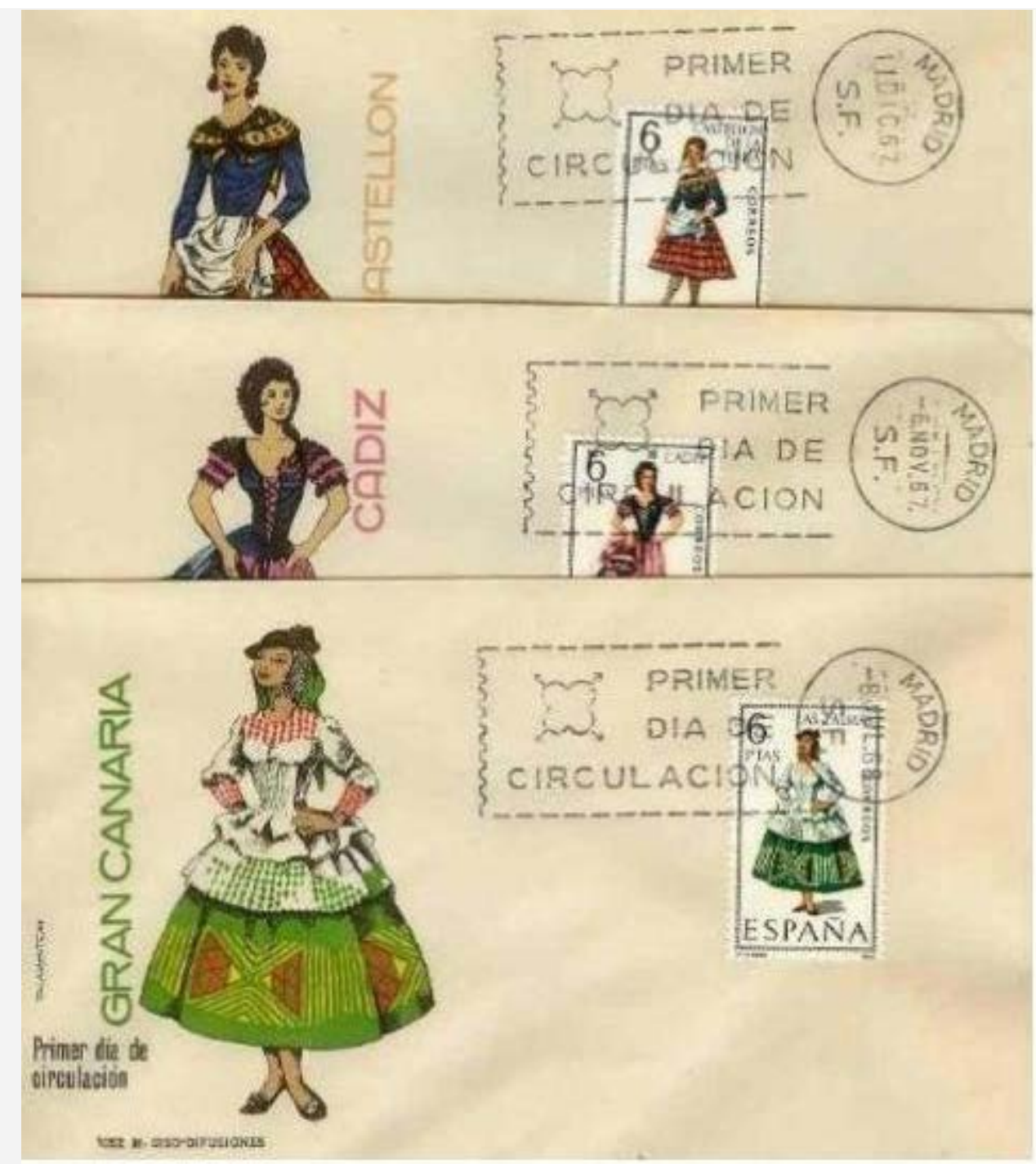

Figura 6. Trajes Regionales de España. Sobres con los dibujos prototipo para la tirada de sellos, 1967-69. Fotografía. Todocolección

La preocupación por la autenticidad del traje regional llevó a establecer incluso un Archivo de Indumentaria de la Sección Femenina, situado en la delegación provincial de Valencia, para custodiar las piezas consideradas excepcionales (Añón y Montolíu 2011: 10). Por otra parte, la especialización de la Sección Femenina en las tareas de costura, que se consideraba una de las dedicaciones más importantes a las que se debían aplicar las mujeres (Domingo 2007), aparte de la confección de canastillas y los cursos de corte y confección, bordados, etc., que impartían las Cátedras Ambulantes y las delegaciones provinciales, tuvo también su aplicación en la confección de los trajes típicos regionales. Así, por ejemplo, en una fecha tan temprana como 1938 se crea, aún bajo el patrocinio de Auxilia Social, el primer taller de artesanía en la localidad de Carbajales (Zamora), conocida por sus famosos bordados tradicionales. En 1940, con la contribución económica de la comarca, se funda en el pueblo un Taller Escuela de Artesanía, regentado por la Sección Femenina, y que siguió desarrollando su labor después de que esta desapareciera.

Pero, al igual que en el asunto de la música folclórica, los resultados obtenidos por la actividad ímproba de la Sección Femenina fueron, en lo que se refiere a la indumentaria tradicional, la mixtificación e incluso la invención de algunos de estos trajes regionales. En las dos figuras que van a continuación puede verse la distancia que llega a alcanzarse por este camino entre una visión y la otra. 


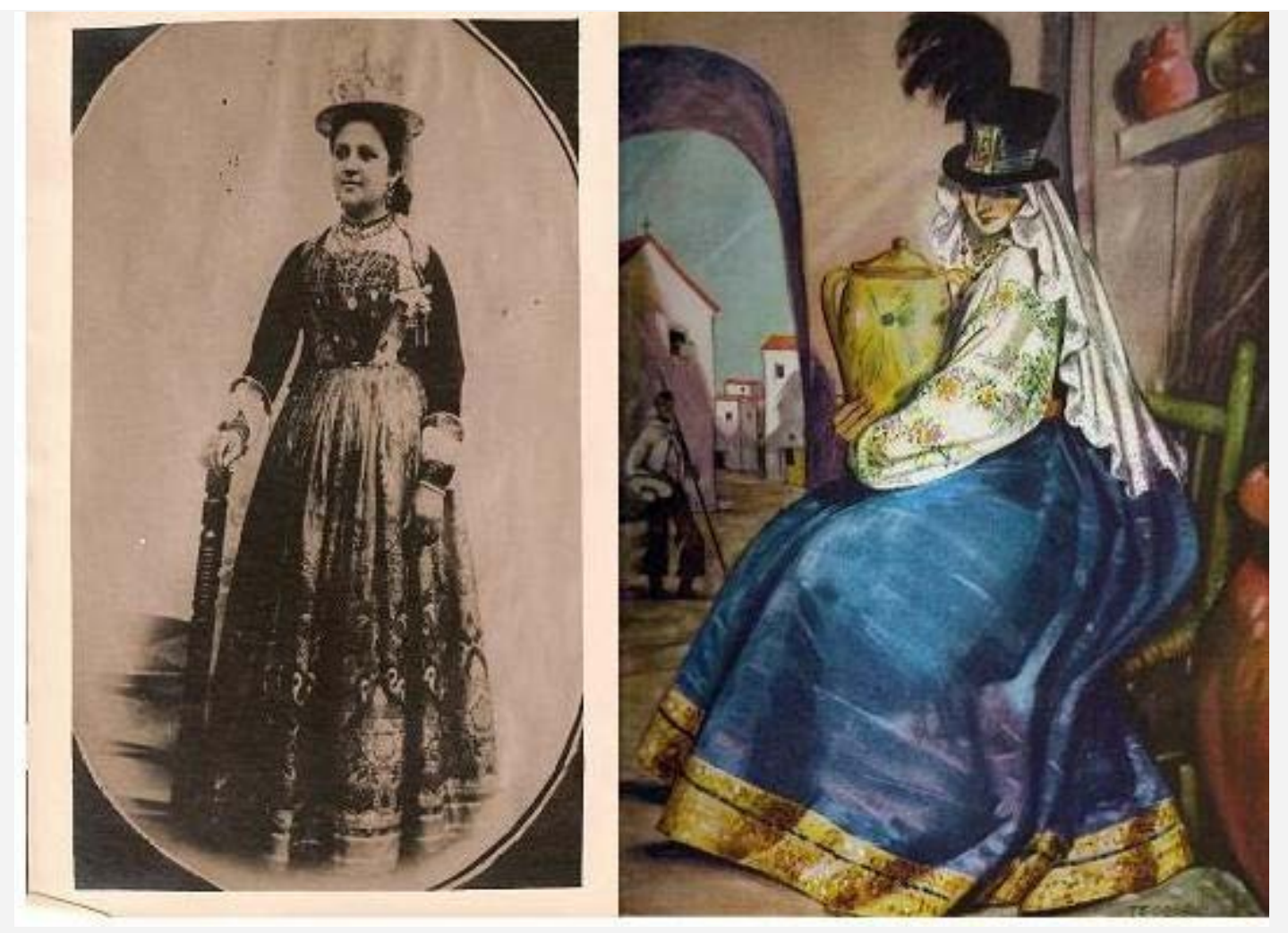

Figura 7a. Traje de Mayordoma de El Cerro del Andévalo (Huelva). Escuela Superior del Magisterio, 1916-1919. Madrid.

Figura 7b. Mayordoma de Huelva, Trajes de España, Barcelona, 1958. Láminas de Teodoro Delgado y glosas de Mariano Rodríguez de Rivas.

En primer lugar debe tenerse en cuenta, como se ha venido viendo a lo largo de toda la exposición, la carencia de preparación especializada de las voluntarias y los mandos de la Sección Femenina en estos asuntos, que podría haberse paliado a lo largo de los años con una formación sistemática. La falta de preparación superior para sus afiliadas mantenida en toda su trayectoria, avala que el objetivo de la organización no era desde luego la investigación folclórica y que su interés por las culturas populares dependía de sus posibilidades de instrumentalización y utilización política, como entretenimiento de las masas y también como complemento de las actividades que se consideraban propias del género femenino.

Pero además, en lo que se refiere al tema de la indumentaria, la atención hacia el traje dependía de su uso como aditamento imprescindible para el espectáculo musical, organizado en torno al núcleo fundamental de los Coros y Danzas, lo que dirigía y condicionaba cualquier trabajo o investigación en este sentido. Los trajes en primer lugar debían ser elegidos por ser propios de una tradición local -con la posibilidad de ser extendida a un ámbito provincial o regional-, más o menos antigua o auténtica, pero cuanto más posible de remontar a orígenes lejanos mejor (por ejemplo, los rodetes del peinado de las valencianas eran vistos como una supervivencia de las damas ibéricas protohistóricas, los faralaes eran puestos en relación con las antiguas civilizaciones micénicas y tartésicas, y el carácter medieval de los trajes femeninos del pirineo aragonés era siempre resaltado). Pero también, a continuación, se seleccionaban por su riqueza o espectacularidad, lo que incidía en la valoración de los que tenían mayor cantidad de aditamentos decorativos (joyas y bordados, por ejemplo, llevados al extremo en los muy "étnicos" trajes de charra salmantina o lagarterana). Así, todos los trajes mostrados eran de "fiesta", ya que los vestidos cotidianos de la gente, incluso de aquellos lugares en los que existían todavía en aquellos momentos particularidades en la indumentaria tradicional, estaban adaptados al trabajo diario y no eran, por tanto, especialmente ricos en joyas ni en adornos.

Por otra parte, muchas de las prendas debieron acomodarse a las funciones específicas a que se destinaban y así, además de los cambios que tenían que ver con la necesaria modestia que era obligatoria para las mujeres españolas durante el franquismo, que descartaba ajustes excesivos a la 
figura y conllevaba cambios en la ropa interior tradicional, también hubo que hacer modificaciones que aliviaran el peso excesivo de la ropa o facilitaran los movimientos del baile. La moda también influyó considerablemente, por ejemplo, en el acortamiento excesivo de las sayas durante las décadas de los años 60 y 70.

Finalmente, la necesidad de que la forma de vestir fuera representativa de una de las regiones en que se había dividido España y que, a su vez, todas y cada una de las provincias tuviera su traje típico fue lo que seguramente contribuyó más a la construcción y reconstrucción de prendas y atavíos completos, que debían incluir en cada caso desde un peinado o tocado específico al ajuar de joyas y un tipo de zapatos y medias propios. Para solucionar este tema hubo que hacer ajustes variados. Muchos trajes locales, ya conocidos de antiguo por su riqueza o sabor local característico, fueron adoptados como símbolo provincial, como ocurrió con el traje de charra que se convirtió en el traje típico de Salamanca, o con el rústico atuendo de las labradoras de la zonas altas de la provincia de Guadalajara que se dulcificó en el inventado traje de "alcarreña".
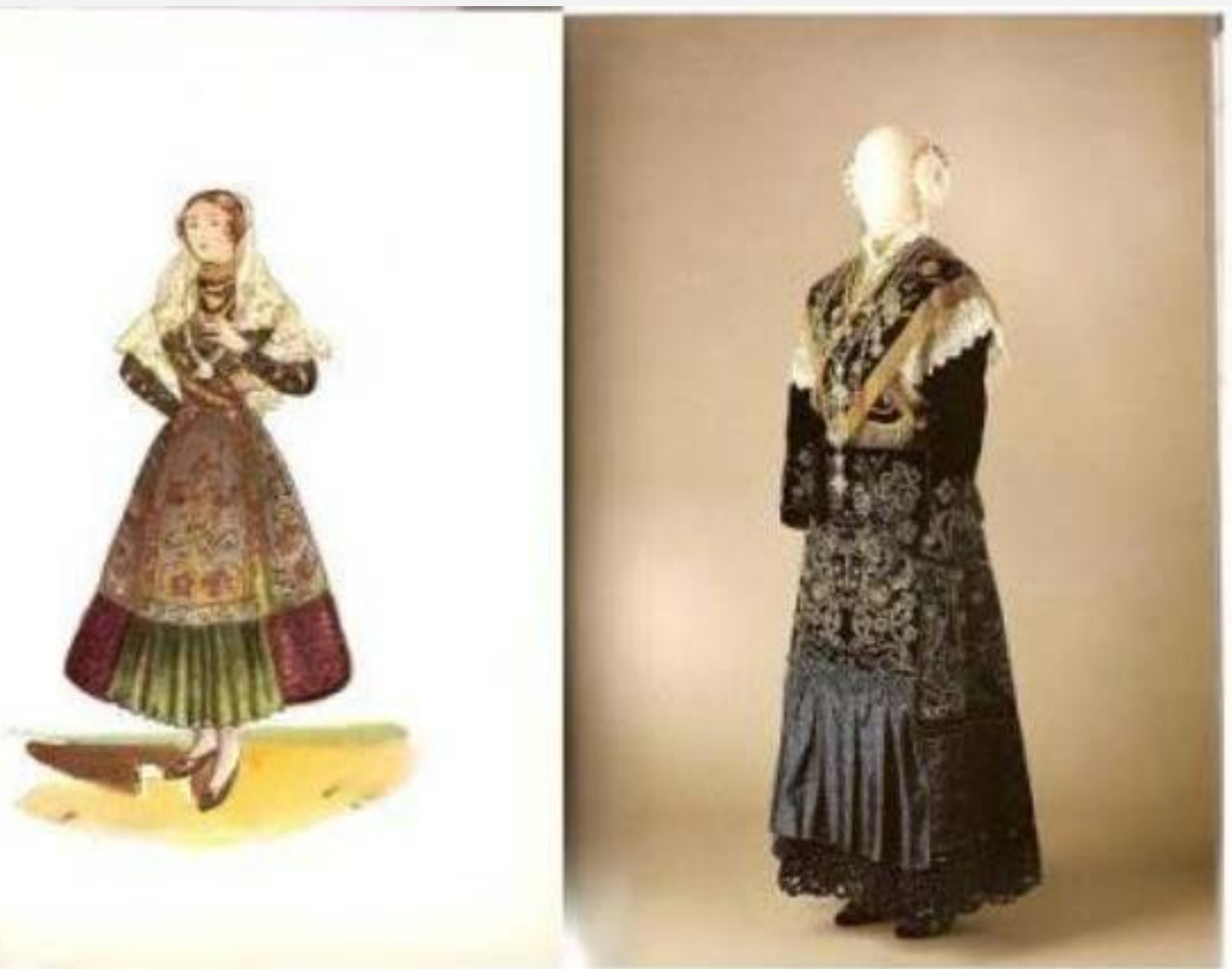

Figura 8a. Traje de Salamanca. Trajes de España. Colección de María Eva Duarte de Perón. 1948. Figura 8b. Charra salmantina, 1920. Museo del Pueblo Español. Moda en Sombras 1991, p. 124. 

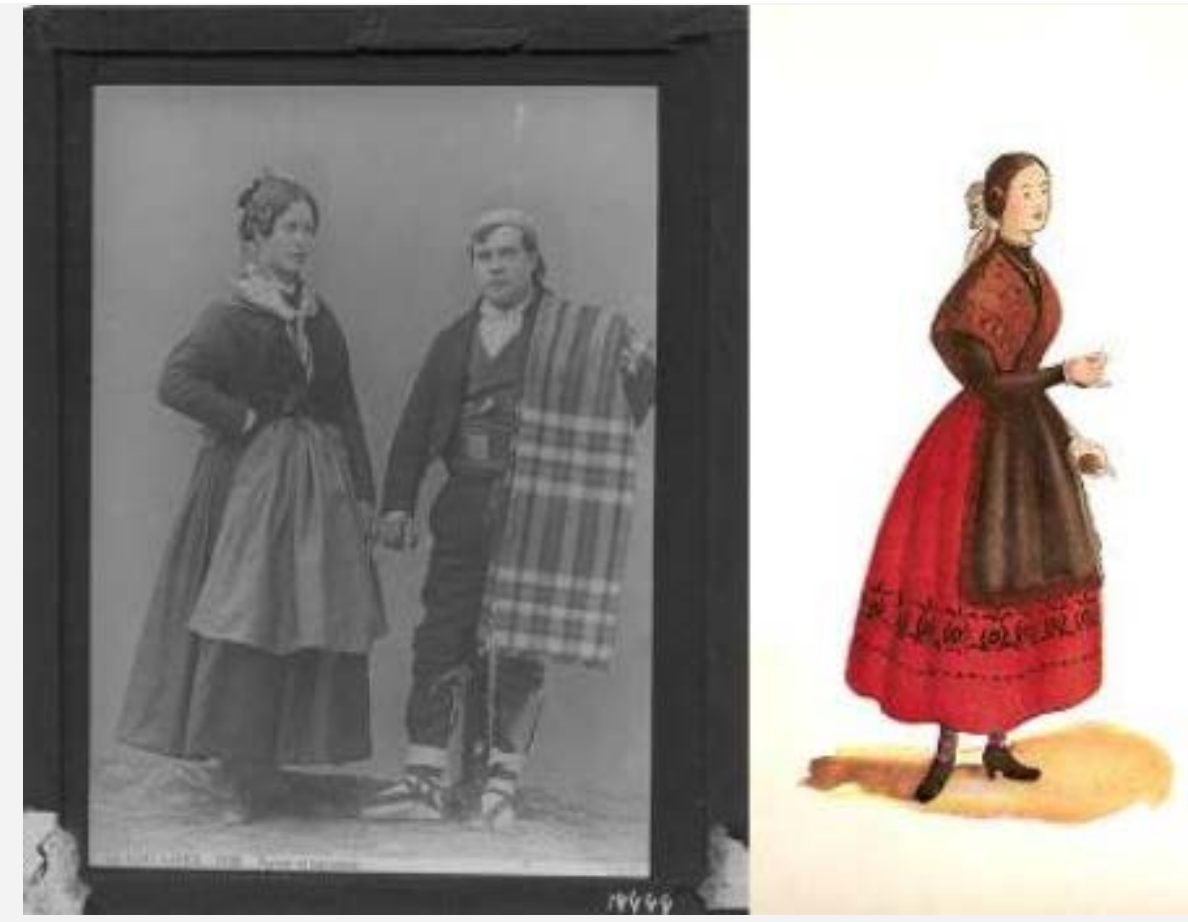

Figura 9a. Pareja de las tierras altas de Guadalajara. Foto de Laurent.

Figura 9b. Traje de Guadalajara. Trajes de España. Colección de María Eva Duarte de Perón. 1948.

En general, observando las representaciones escalonadas de los trajes típicos con que contamos, lo que puede observarse en las de la Sección Femenina es una idealización absoluta, en sintonía con el resto de sus representaciones "ideales" de la mujer y del país en que estaban empeñadas.

No se trata, así, de que la foto de Laurent que retrata a dos mozas de la Sierra durante la boda de Alfonso XII represente el auténtico traje madrileño; se trata de que la idealización del traje de madrileña de estilo goyesco que se reproduce en el libro Trajes de España. Colección de María Eva Duarte de Perón (1948), estampado, como el resto de las provincias, por V. Viudas, representa claramente una construcción cultista de una indumentaria típica de la capital de España, acorde con su rango e importancia y, desde luego, muy estética para lucir en el baile de boleros u otras danzas también denominadas "españolas". 


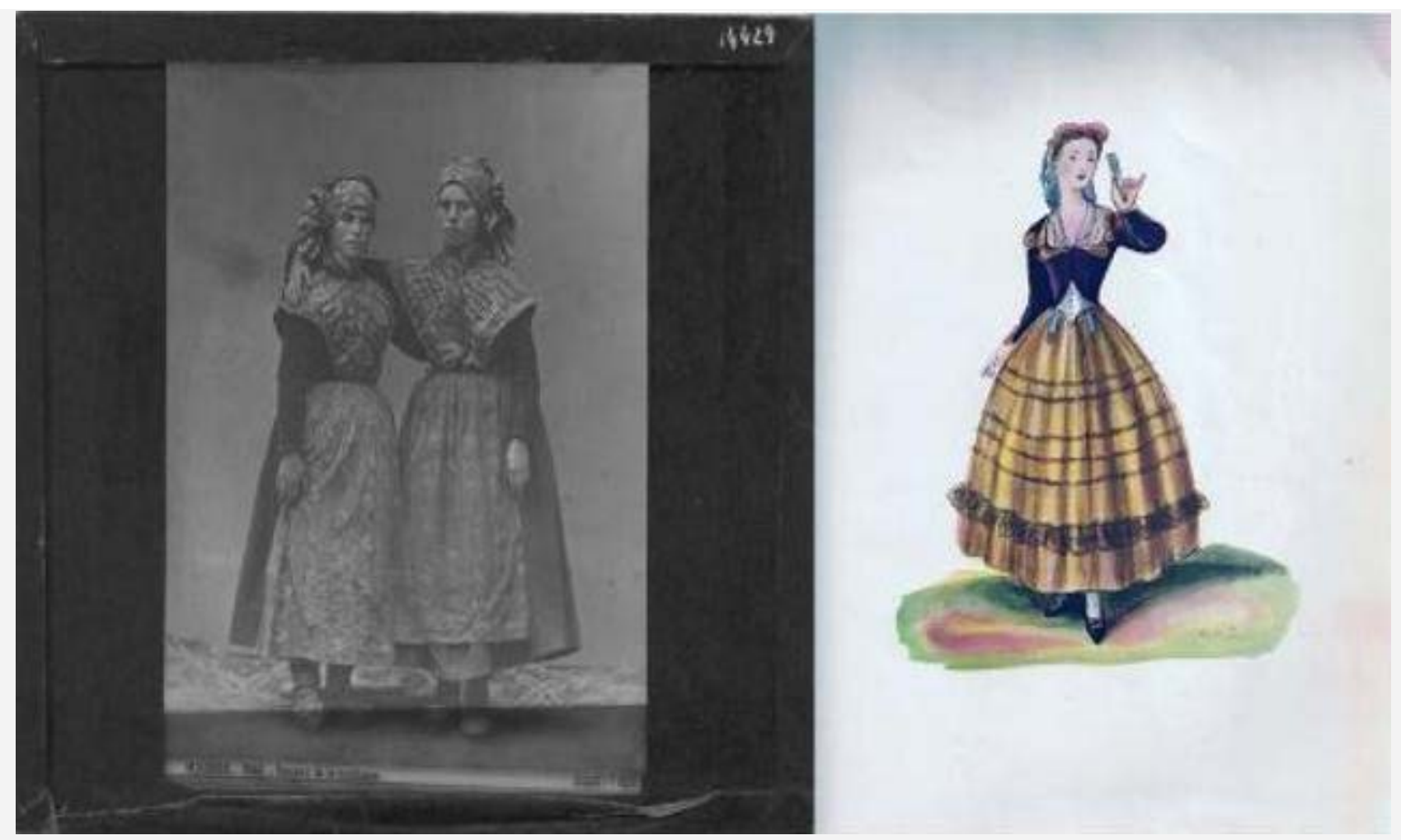

Figura 10a. Jóvenes serranas. Madrid. Foto de Laurent.

Figura 10b. Traje de Madrid. Trajes de España. Colección de María Eva Duarte de Perón. 1948.

El mismo tono idealizado y remitente a viejas ideas y tópicos exotistas sobre el carácter original de la cultura popular española que aparece en los grabados de trajes y en otras reconstrucciones materiales (Cea y otros 1986), puede verse también en los trabajos escritos; por ejemplo, en la descripción que se hace en el libro citado arriba del traje de Granada:

"La gitana de Granada de seda roja chillona o amarilla, con peinecillos de colores, baila mientras cae la tierra en sus cuevas del Sacro Monte, una tierra amarilla como el ruedo de la Plaza de toros, donde ella enciende sus velones de plata y coloca sus colchas de color carmesí sobre la cama de hierro dorado, bajo el cromo de un Santo con una verde rama de romero bendito.- Pero hay también la granadina de los Cármenes. Que acaso recogió las pepitas de oro del Darro o del Genil, como los restos de una corona mora, con su jubón de terciopelo y su falda de seda rosa como el pálido jugo de la fruta de su nombre bajo el Mulhacén nevado de su blanca mantilla.- Tiene algo de morisca y cristiana, perdida ya la languidez oriental de las fuentes y de las albercas entre arrayanes de la Alhambra, donde la dorada caligrafía árabe sobre el estuco azul canta la gloria de Alá y hay leyendas de sedientos leones del desierto escritas en los tazones de sus surtidores".

Si se han señalado algunos rasgos de la obra de la Sección Femenina que inciden en su carácter intermediador e instrumentalizador del folclore para fines de propaganda y educación en los valores del régimen, hay que señalar que su obra más duradera Los Coros y Danzas de España no solo tuvieron un considerable éxito en su época, tanto dentro como fuera de España, sino que en buena parte han tenido continuidad en muchos de los grupos de música y danza folclórica que han existido después en nuestro país. El reciclaje político de algunos de estos grupos y, sobre todo, la experiencia organizativa y el acervo de información y conocimiento que tenían muchas de las personas que trabajaron en la organización falangista, hizo que fueran la base de los desarrollos folclóricos posteriores en muchas zonas (cf. Añón y Montolíu 2011: 26-29). Así pues, y aunque durante la Transición hubo una indudable reacción en contra de la organización falangista, y una crítica general de sus métodos y resultados, en este, como en otros terrenos de la vida intelectual española, puede decirse que no hubo una total ruptura, sino más bien continuidad, y que buena parte de lo que se presenta hoy en España como folclore tradicional, en una sociedad abrumadoramente modernizada y alejada de las raíces de la cultura tradicional, es producto de la recreación estilizada y transformada de la realidad mediante la acción 
políticamente orientada por la Sección Femenina, y esto mismo podría decirse concretándolo en los trajes regionales (Casero 2000: 118).

Por otro lado, en lo que tiene que ver con los trajes, su elaboración en el ámbito de control de la Sección Femenina, siguiendo hasta donde era posible, y en muchos casos copiando fielmente, los patrones, los materiales y las técnicas tradicionales, contribuyó considerablemente no solo a la conservación de los ejemplares antiguos, sino al mantenimiento de muchos trabajos artesanos relacionados, por ejemplo, con la orfebrería, los tejidos y los bordados, y dio lugar al resurgimiento de una artesanía que igualmente se mantiene en la actualidad en la mayor parte de las regiones, formada por talleres dedicados a la elaboración de los trajes regionales de exhibición, que siguen usándose hoy profusamente como medio de representación de la identidad cultural en todas las Autonomías. Las bordadoras, costureras, tejedoras, joyeros, zapateros, encajeros, etc. que sabían elaborar las prendas y los objetos propios de su cultura tradicional en muchas zonas pudieron seguir desarrollando su labor gracias al "mercado" que les proporcionó la Sección Femenina y pudieron, también gracias a su ayuda, seguir trasmitiendo sus conocimientos y técnicas.

Con todo, el legado de la Sección Femenina en lo que se refiere al folclore es todavía mal conocido. Y, aun menos que sus actividades musicales se ha estudiado lo que tiene que ver con los trajes regionales. A pesar de la aparición en los últimos años de libros importantes, apoyados en archivos provinciales y en la documentación de la Secretaría General del Movimiento depositada en el Archivo General de la Administración, en este desconocimiento ha incidido, entre otras causas, la forma abrupta en que se disolvió la organización en 1977 y la aparición de varias asociaciones sucesoras, como la Asociación Nueva Andadura, nacida para salvaguardar y mantener la herencia y el legado documental de la Sección Femenina (Súarez Férnandez 1993).

Una muestra de lo anterior es la dificultad para localizar una colección completa de los trajes regionales usados por los Coros y Danzas de la Sección Femenina. La existencia de un Museo del Traje, sucesor del antiguo Museo del Pueblo Español (Carretero 2004), llevaría a suponer que esta institución sería la más indicada para conservar esa colección. Sin embargo, en el Museo solo se recibieron, al disolverse la organización, un gran número de labores de costura (mantelerías, muestras de bordado, diseños de papel y piezas terminadas), una colección de velos de los usados para ir a misa y una serie de muñecas de fieltro vestidas con los trajes regionales españoles. Además se ingresaron unas pocas fotografías que llevan el sello de la Sección Femenina (1). Por otra parte, en 1986-87, Pilar Primo de Rivera donó al Museo un conjunto de más de doscientas piezas, formado por prendas de vestir y joyas asociadas a la indumentaria tradicional (Herradón 1998: 207), algunas de ellas con una etiqueta que marca su procedencia del Castillo de la Mota. Así, por ejemplo, aparecen como procedentes de esta donación, la enagua del traje de pescadora gallega (números de inventario MT02315, MT02328; MT06180, MT15112, MT18563) y la basquiña del traje de mujer de Ansó (Huesca) (Seco 2008) (números de inventario MT05741, MT05744, MT18527, MT18529; MT18537).

Ante la dificultad para localizar estos trajes, podemos recurrir para documentar su enorme riqueza y la minuciosidad con que estaban compuestos, a la colección que fue regalada a María Eva Duarte de Perón durante su viaje a España en el verano de 1947. Como es sabido, en 1946 el Presidente Perón rompió el bloqueo impuesto por las Naciones Unidas al gobierno de Franco permitiendo la compra del excedentario trigo argentino y haciendo una generosa donación del mismo al pueblo español. Con ese motivo, durante una gira europea, su carismática esposa, visitó España entre el 10 y el 26 de junio de 1947. Entre los múltiples agasajos que recibió -fue condecorada por Franco con la Gran Cruz de Isabel la Católica- figuraban algunos actos y visitas con especial protagonismo de la Sección Femenina. Así, ya en el mismo aeropuerto de Barajas estaba prevista la actuación (que no se pudo llevar a cabo por problemas de horario) de 1.000 de sus chicas. Junto a la siempre acompañante mujer de Franco, Eva Duarte visitó también el Castillo de la Mota. Pero, lo más destacado fue la organización de un "Homenaje de las provincias de España", consistente en un espectáculo folclórico celebrado en la noche del 12 de junio en la Plaza Mayor de Madrid. Al finalizar este, se hizo la ofrenda de las cincuenta provincias de España, con la entrega a Eva Perón de unas cajas de mimbre conteniendo las réplicas, adaptadas a las medidas de la primera dama, de los trajes típicos de las cincuenta provincias españolas. 


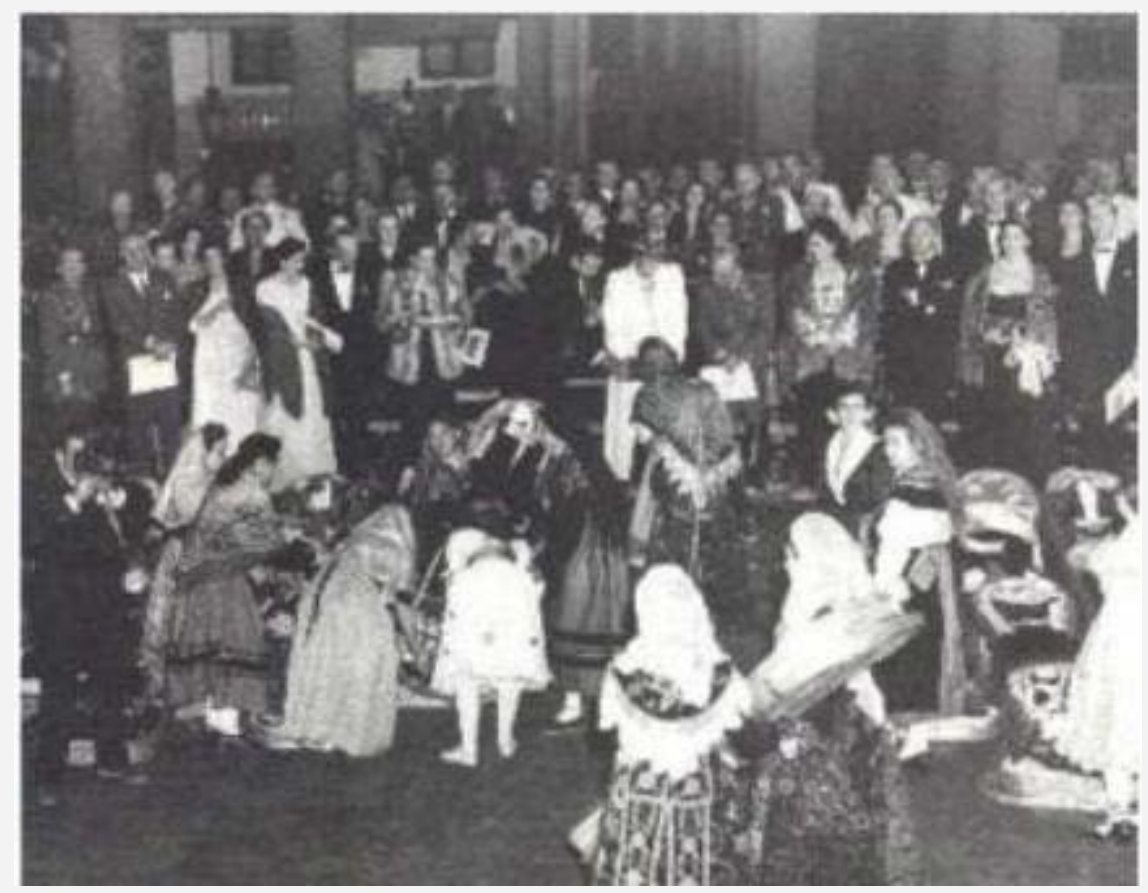

Figura 11. Entrega a $\mathrm{M}^{\mathrm{a}}$ Eva Duarte de Perón de los trajes típicos españoles, Madrid, 12 de junio de 1947.

El acto es narrado como sigue en el libro de Enrique F. Widmann-Miguel que reproduce la crónica del viaje por España: "Las representantes de cada provincia se acercaron con canastas de mimbre en forma de mujer, dentro de las cuales se encontraban los trajes típicos originales de cada provincia, confeccionados especialmente a su medida con géneros tradicionales auténticos guardados durante años, que fueron obsequiados a la Señora de Perón, incluyendo accesorios y joyas legítimas" (WidmannMiguel 2009: 41).

En esta ocasión, y en el contexto del máximo esfuerzo hecho por la dictadura para ofrecer su cara más amable al exterior, que conllevó una agenda de visitas, fiestas y regalos continuos para la primara dama argentina, vemos de nuevo la aparición en un primer plano del tipismo folclorista -no solo representado por la Sección Femenina, sino también por las instituciones de promoción de la artesanía, las agrupaciones de Educación y Descanso, y otros agentes- como uno de los elementos constituyentes más importantes en la autorepresentación de la nación y del régimen de Franco a través de ella.

En cuanto a la colección de indumentaria, constituye un conjunto formado por 728 piezas dado que cada traje incluye la ropa interior, el calzado, el aderezo de joyas, el tocado, etc. Parece ser que, junto a las cajas originales de mimbre que se conservan, iban también maniquíes, cuyos rostros representaban la fisonomía de las distintas regiones, pero estos resultaron perdidos en el teatro Colón de Buenos Aires (Camps 2002). Tras el regreso a Argentina de Eva Perón, la colección -que parece que tenía desde su origen un fin museográfico- se mostró en el Museo Nacional de Arte Decorativo y posteriormente quedó en la sede de la Presidencia de la Nación hasta 1967, en que se trasfirió al Museo de Arte Español Enrique Larreta de Buenos Aires, donde quedó depositada y custodiada. El Museo hizo una exposición de los trajes en 1985 de la que se editó un libro-catálogo, y una muestra completa de la colección se ha podido ver en Buenos Aires en 2002, diseñada por la museóloga María Teresa Dondo de Barcia y con textos de la investigadora del Museo Gloria Agid (cf. Lescano 2002).

Así, después de todo y de un modo paradójico, tenemos que una de las informaciones más completas, que yo conozca, sobre los trajes regionales españoles de la Sección Femenina que está disponible al público es la descripción de muchas de las piezas que componían cada traje provincial de los regalados a Eva Perón, que se ofrece a través del portal de internet Acceder (Red de Contenidos Digitales del Patrimonio Cultural del Ministerio de Cultura argentino). 


\section{Moda e indumentaria.13/cd:Museo de Arte_Español Enrique Larreta.67}

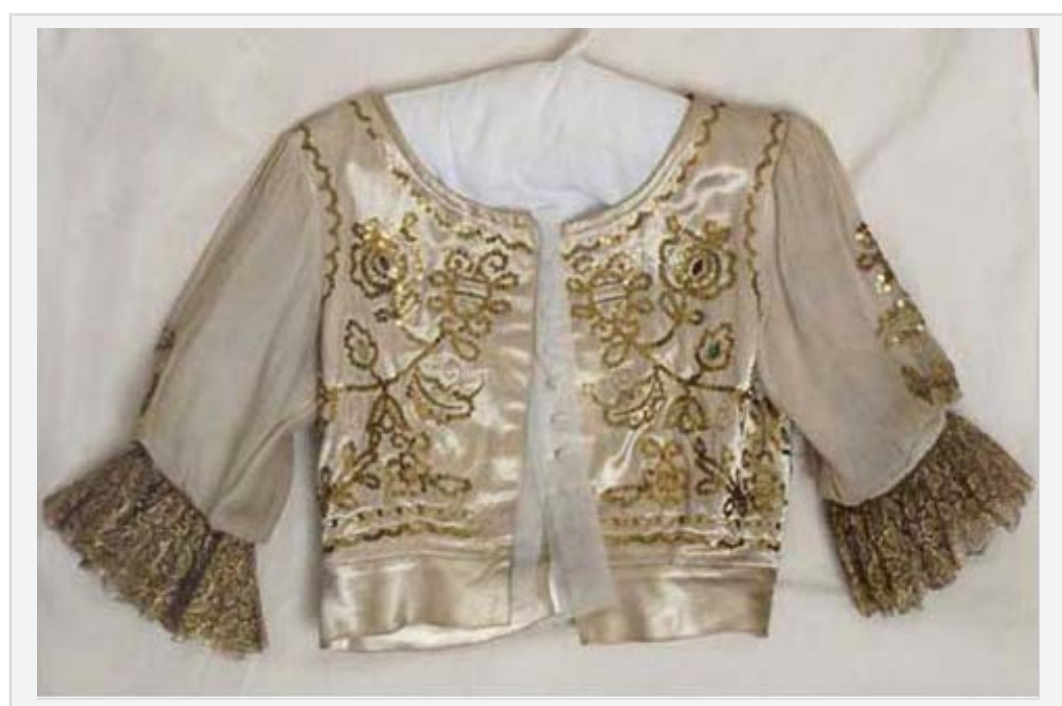

Figura 12. Jubón del traje de Murcia. Museo Larreta. Buenos Aires.

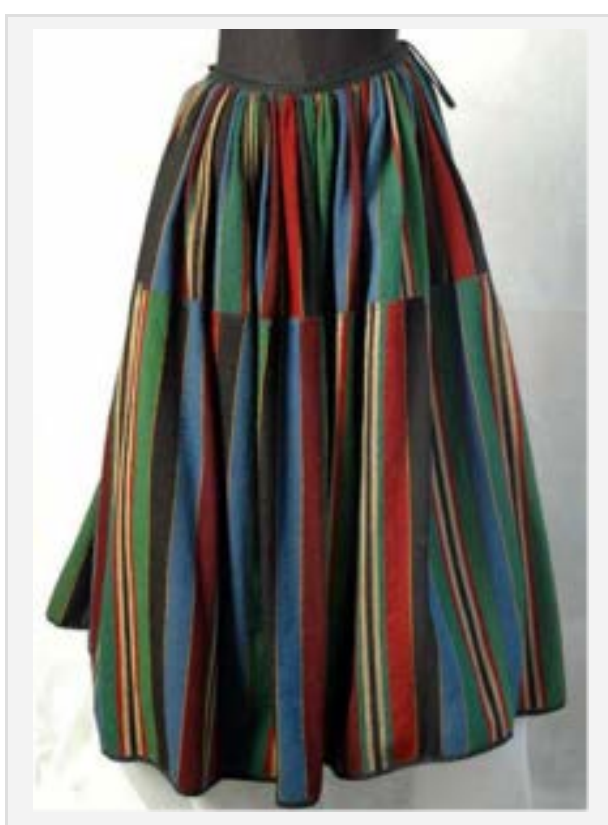

Figura 13. Sayas del traje canario. Museo Larreta. Buenos Aires.

Por este catálogo, se puede apreciar la riqueza y la exhaustividad con que se había compuesto cada traje, que incluía desde los canastos, especialmente diseñados para el almacenaje y transporte individualizado, a los joyeros en que se guardaban los aderezos, las horquillas de plata diferentes para cada tipo de moño, los pendientes, las cintas de terciopelo para colgar las cruces, o las trenzas de pelo postizo (rubio) que debían acompañarlos en algún caso. Como ejemplo de la descripción que acompaña la ficha catalográfica de cada pieza en el museo argentino, transcribo la correspondiente a una pieza muy conocida de la indumentaria popular española, el traje de fiesta de las mayordomas de Zamarramala (Segovia):

"MITRA. Pertenece al traje regional de Segovia -provincia perteneciente a Castilla y León, Españaque está compuesto por: MITRA (2) de terciopelo negro ricamente bordada y rematada con una gran 
borla de color y a los lados doce botones dorados llamados "apóstoles". Amplio tul blanco guarnecido con puntilla de malla bordada que cierra sobre jubón con broche de corales. BASTÓN DE MANDO del municipio de Zamarramala, con engarce de metal dorado. JUBÓN de raso negro, abrochado con cordones y guarnecido por pechera, cuello y puños blancos de linón con broderie y galones de mostacilla y pasamanería. En los puños cuatro botones de filigrana de plata. FALDA de paño rojo con "tiranas" (guardas) de terciopelo negro y galones de pasamanería y mostacilla. MANDIL de brocado y terciopelo negros, bordeado por "puntas segovianas" de diseño similar al diseño de las almenas islámicas. MEDIAS blancas de punto calado. ZAPATOS de terciopelo negro con hebillas de metal labrado".

La visión de esta riqueza y la calidad artesanal de las piezas que puede observarse en la colección argentina, nos muestra un conjunto patrimonialmente valioso y nos habla de la labor cultural que, en paralelo a la actividad política que siempre fue la base y el motivo de cualquiera de sus actividades organizativas, desarrolló la Sección Femenina de Falange en sus cuarenta y tres años de vida y esforzado trabajo. A la vez, la historia de la colección de los trajes de las provincias españolas regalados a Eva Perón, nos enseña de qué manera la cultura popular y tradicional, como cualquier otra parte del patrimonio, tiene una vida, unos usos y unas posibilidades que van más allá de sus propios valores intrínsecos y dependen de la forma en que el pasado es considerado relevante para el presente; en una palabra del modo en que adquiere significación política. Finalmente, la posibilidad de consultar en Internet un catálogo profesional de una colección indumentaria de origen español a partir de un museo radicado en Buenos Aires, junto a la desaparición (al menos para el público general) de los trajes y el resto del legado folclórico acumulado por la Sección Femenina de Falange, pone en evidencia la dificultad de la gestión de nuestros bienes patrimoniales que tienen que ver con la postguerra y la dictadura. Son ejemplo, en fin de cómo cualquier objeto material puede ser revestido de significados y sentidos simbólicos distintos y hasta contrapuestos.

\section{Notas}

1. Agradezco a María Antonia Herradón, Conservadora del Museo del Traje, sus informaciones respecto a las colecciones de procedencia de la Sección Femenina que existen en el Museo.

2. Debería mejor denominarse montera, toca o tocado a este sombrero típico.

\section{Bibliografía}

Aguilera, Emiliano

1948 Los trajes populares de España vistos por los pintores españoles. Barcelona, Omega.

Alpuente, Moncho

2009 "Mujeres de azul", Mujeres de azul. Madrid, Ministerio de Cultura: 13-16.

Añón Baylach, Amparo (y Violeta Montolíu Soler)

2011 Los Coros y Danzas de España. Transmisores del patrimonio cultural valenciano.

http://www.racv.es/files/Los-coros-y-danzas.pdf [consulta 8-10-2012]. 
1993 "Volkskunde" ou l'ethnologie allemande. París, Éditions de la Maison des sciences de l'homme.

Berlanga Fernández, Miguel A.

2001 "El uso del folclore en la Sección Femenina de la Falange: el caso de Granada", en Ignacio L. Henares y otros (eds.), Dos décadas de cultura artística del franquismo (1936-1956). Granada, Universidad de Granada, vol. 2.

Box, Zira

2008 La fundación de un régimen. La construcción simbólica del franquismo. Madrid, Universidad Complutense.

Camps, Sibila

2002 "Cuarenta trajes para Eva Perón", Clarín. Buenos Aires, 7 de junio.

http://www.clarin.com [consulta 2-4-2009].

Carretero Pérez, Andrés

2004 "El Museo del Traje. Centro de Investigación del Patrimonio Etnológico", Revista de Museología (Madrid), no 29: 88-95.

Casero, Estrella

2000 La España que bailó con Franco. Coros y Danzas de la Sección Femenina. Madrid, Editorial Nuevas Estructuras, S.L.

Castro, Luis

2008 Héroes y caídos. Políticas de la memoria en la España contemporánea. Madrid, La Catarata.

Cea, Antonio (y otros)

1986 Tipos y trajes de Zamora, Salamanca y León. Zamora, Caja de Zamora.

Domingo, Carmen

2007 Coser y cantar. Las mujeres bajo la dictadura franquista. Barcelona, Lumen.

Fernández Jiménez, M. Antonia

2008 Pilar Primo de Rivera. El falangismo femenino. Madrid, Síntesis.

Ferrer Senabre, Isabel

2011 "Canto y cotidianidad: visibilidad y género durante el primer franquismo", Trans-Revista Transcultural de Música (Madrid), nº 15.

http://www.sibetrans.com/trans [consulta 20-09-2012].

Herradón Figueroa, M. Antonia

1998 "La joyería española en el Museo nacional de Antropología. Formación y carácter de un mito", en Letizia Arbeteta (coord.), La joyería española de Felipe II a Alfonso XIII en los Museos Estatales. Madrid, Editorial Nerea.

Hobsbawm, Eric J.

1983 "Introduction", en Eric J. Hobsbawm y Terence Ranger (eds.), The Invention of Tradition. Cambridge, Cambridge University Press.

Hoyos Sancho, Nieves de

1971 "Fondos de Vizcaya y Guipúzcoa en el Museo del Pueblo Español”, Munibe XXIII, ํ 4: 523-532.

Lescano, Victoria

2002 "Evita maja". Página12. Buenos Aires, 26 de julio.

http://www.pagina12.com.ar [consulta 2-4-2009].

Lizarazu de Mesa, M. Asunción 
1996 "En torno al folclore musical y su utilización: el caso de las Misiones Pedagógicas y la Sección Femenina", Anuario Musical (Barcelona), nº 51: 233-245.

Llorente, Ángel

1995 Arte e ideología en el franquismo (1936-1951). Madrid, Visor.

Manrique Arribas, Juan C.

2010 Las profesoras de Educación Física en la Sección Femenina segoviana. Buenos Aires, Miño y Dávila.

Marías Cadenas, Sescún

2011 Por España y el campo. La Sección Femenina en el medio rural oscense (1939-1977). Zaragoza, Instituto de Estudios Altoraragoneses.

Menéndez Pidal, Ramón

1953 "Prólogo", Canciones y danzas de España. Madrid, Sección Femenina.

Moda en sombras

1991 Madrid, Ministerio de Cultura.

Ofer, Inbal

2009 Señoritas in Blue. The Making of a Female Political Elite in Franco's Spain. Brighton-Portland, Sussex Academic Press.

Ortiz García, Carmen

1988 "Contribución de la Escuela Superior del Magisterio al estudio del traje regional español (19141936)", Revista de Dialectología y Tradiciones Populares (Madrid), nº XLIII: 445-456.

1998 "Folclore y franquismo", en Rafael Huertas y Carmen Ortiz (coords.), Ciencia y fascismo. Madrid, Doce Calles: 161-179.

Otero, Luis

1999 La Sección Femenina. Madrid, Edaf.

Pérez Moreno, Heliodoro M.

2004 Una escuela viajera. La Cátedra Ambulante de la Sección Femenina en Huelva (1956-1977). Huelva, Diputación.

Primo de Rivera, Pilar

1983 Recuerdos de una vida. Madrid, Ediciones Dyrsa.

Richmond, Kathlen

2004 Las mujeres en el fascismo español. La Sección Femenina de Falange, 1934-1959. Madrid, Alianza.

Roca i Girona, Jordi

1996 Madre y esposa. La construcción del género femenino en la postguerra española. Madrid, Ministerio de Cultura.

Rodríguez López, Sofía

2010 El patio de la cárcel. La Sección Femenina de FET-JONS en Almería (1937-1977). Sevilla, Fundación Pública Andaluza Centro de Estudios Andaluces.

Sampelayo, M. Josefa

1969 "Labor de la Sección Femenina en el resurgimiento del folclore español", en Etnología y Tradiciones Populares. Zaragoza, Institución Fernando el Católico: 99-101.

Seco Serra, Irene 
2008 "Trajes seculares: El traje femenino del valle de Ansó y la formación de los modelos de indumentaria popular", Indumenta (Madrid), nº 1: 85-103.

Suárez Fernández, Luis

1993 Crónica de la Sección Femenina y su tiempo. Madrid, Asociación Nueva Andadura, $2^{a}$ ed.

Sutil Pérez, José M.

1997 Maragatos en un desfile. León, Ediciones Leonesas S. A.

Trajes de España

1958 Láminas de Teodoro Delgado y glosas de Mariano Rodríguez de Rivas. Barcelona, Luis de Caralt.

Trajes de España: Colección de Eva María Duarte de Perón

1948 Buenos Aires, Museo Nacional de Arte Decorativo.

Valadés Sierra, Juan

1994 "La indumentaria como símbolo regional. La tradición inventada en el caso del traje femenino de Montehermoso", Revista de Dialectología y Tradiciones Populares (Madrid), no 49 (1): 91-118.

Vega, Jesusa

2002 "El traje del pueblo, Ortiz Echagüe y el simulacro de España", José Ortiz Echagüe en las colecciones del Museo nacional de Antropología. Madrid, Ministerio de Educación, Cultura y Deporte: 1768.

2005 "De la estampa a la fotografía: el traje regional y el simulacro de España", en Carmen Ortiz, Cristina Sánchez-Carretero y Antonio Cea (coords.), Maneras de Mirar. Lecturas antropológicas de la fotografía. Madrid, CSIC: 61-82.

Viejo-Rose, Dacia

2011 Reconstructing Spain: Cultural Heritage and memory alter Civil War. Brighton, Sussex Academic Press.

Widmann-Miguel, Enrique F.

2009 Eva Perón en España. Buenos Aires.

http://www.slideshare.net/carceru/eva-pern-en-eespaa-enrique-f-widmannmiguel-2009. 